\title{
Recombinant Adiponectin Peptide Ameliorates Cortical Neuron Damage Induced by Chronic Cerebral Hypoperfusion by Inhibiting NF-kB Signaling and Regulating Microglial Polarization
}

li'an Huang ( $\nabla$ huanglian1306@126.com )

Jinan University First Affiliated Hospital https://orcid.org/0000-0002-0416-7532

Wenxian Li

Xi'an Jiaotong University

Di Wei

The Fourth Military Medical University

Zheng Zhu

University of California Davis

Shuqin Zhan

Xi'an Jiaotong University

Ru Zhang

Xi'an Jiaotong University

Huqing Wang

Xi'an Jiaotong University

Guilian Zhang

Xi'an Jiaotong University

\section{Research}

Keywords: Chronic cerebral hypoperfusion, Adiponectin, microglial polarization, neuron damage, NF-KB

Posted Date: January 1st, 2021

DOI: https://doi.org/10.21203/rs.3.rs-137422/v1

License: (c) (i) This work is licensed under a Creative Commons Attribution 4.0 International License. Read Full License 

cerebral hypoperfusion by inhibiting NF-אB signaling and regulating microglial polarization

3

Wenxian Li ${ }^{1 \uparrow,}$, Di Wei ${ }^{2 \pi}$, Zheng Zhu ${ }^{3 \pi}$, Shuqin Zhan ${ }^{1}$, Ru Zhang ${ }^{1}$, Huqing Wang ${ }^{1}$, Guilian Zhang $^{1^{*}}$, Li'an Huang ${ }^{* *}$

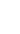

${ }^{1}$ Department of Neurology, The Second Affiliated Hospital, Xi'an jiaotong University, Xi'an, Shanxi, China.

${ }^{2}$ Department of Urology, Xijing Hospital, The Fourth Military Medical University, Xi'an, Shanxi, China.

${ }^{3}$ Department of Internal Medicine, Division of Hematology/Oncology, University of California Davis, Sacramento, CA 95817, USA.

${ }^{4}$ Department of Neurology, The First Affiliated Hospital, Jinan University, Guangzhou, Guangdong, China.

I These authors contributed equally to this study.

* Correspondence:

Prof. Guilian Zhang and Li'an Huang zhg1_2006@126.com

Department of Neurology, The Second Affiliated Hospital, Xi'an Jiaotong University, XiWu Avenue, Xin Cheng District, Xi'an, Shaanxi, 710004, China huanglian1306@126.com 
Department of Neurology, The First Affiliated Hospital, Jinan University, 613 HuangPu Avenue West, Tian He District, Guangzhou, Guangdong, 510632, China

\section{Abstract \\ Background}

Chronic cerebral hypoperfusion $(\mathrm{CCH})$ is common in multiple central nervous system diseases that are associated with neuronal death and cognitive impairment. Microglial activation-mediated polarization changes may be involved in $\mathrm{CCH}$-induced neuronal damage. Adiponectin (APN) is a fat-derived plasma protein that affects neuroprotection. This study investigated whether a recombinant APN peptide (APN-P) improved the cognitive function of $\mathrm{CCH}$ rats by regulating microglial polarization in the cortex.

\section{Methods}

A CCH rat model was established through bilateral common carotid artery occlusion (BCCAO) surgery. An antibody microarray was used to analyze differentially expressed proteins in the cerebral cortex of $\mathrm{CCH}$ rats compared to the sham rats. APN-P and a solvent control were used to intervene at different time points. Western blotting and immunofluorescence staining were conducted to examine the status of microglial polarization in different treatment groups. qRT-PCR was used to detect the expression levels of inflammatory and anti-inflammatory genes. Neuronal morphology was assessed via Nissl staining, and cognitive function was assessed with the Morris water maze test. In vitro, by inhibiting the expression of NF-אB in BV2 microglia and using Transwell co-culture systems of BV2 microglia and neurons, the effects of APN-P on neuroprotection and the underlying mechanism were investigated. 


\section{Results}

In the cortical microglia of 12-week-old CCH rats, the expression of APN protein was significantly downregulated compared to the sham rats. $\mathrm{CCH}$ damages neurons and activates cortical microglial polarization to an M1-type by upregulating inflammatory factors. APN-P supplementation upregulated APN expression in cortical microglia, with neuronal survival as well as microglial polarization from an M1 toward an M2 phenotype in $\mathrm{CCH}$ cortex. In vivo and in vitro experiments revealed that APN-P promoted the expression of anti-inflammatory factors and neuronal survival by inhibiting NF- $\mathrm{KB}$ signaling, thus improving the cognitive function in $\mathrm{CCH}$ rats.

\section{Conclusions}

Our study revealed a novel mechanism by which APN-P suppresses the NF-kB pathway and promotes microglial polarization from M1 toward the M2-type to reduce neuron damage in the cortex after $\mathrm{CCH}$.

Keywords: Chronic cerebral hypoperfusion; Adiponectin; microglial polarization; neuron damage;

$\mathrm{NF}-\kappa \mathrm{B}$

\section{Background}

While the pathophysiology and mechanisms of acute stroke are of scientific and clinical importance, few experimental systems can recapitulate the ischemic injury that results from chronic cerebral hypoperfusion $(\mathrm{CCH})$ [1]. $\mathrm{CCH}$ is a state of chronic cerebral blood flow $(\mathrm{CBF})$ reduction that contributes to numerous neurological illnesses [2], and can result from disorders affecting the cerebral vascular system [3]. The long-lasting reduction in CBF will lead to neuronal damage 
followed by cognitive and memory deficits [2]. Cognitive injury secondary to $\mathrm{CCH}$ is pervasive and likely underrecognized $[1,4]$. To date, there is no successful drug treatment that prevents $\mathrm{CCH}$ induced cognitive deficits $[5,6]$. Although improving cerebral perfusion can be an effective intervention, it is limited to only early stages of $\mathrm{CCH}$.

In response to $\mathrm{CCH}$, a chain of homeostatic interactions occur in the brain, including neuroinflammation, oxidative stress, mitochondrial dysfunction, disorder of neurotransmitter system and lipid metabolism, and changes in expression of growth factors, which culminate in neuronal death $[4,7]$. Unfortunately, the neurorestorative potential of the adult brain is very limited [8]. Previous studies have reported that neuronal death is the key factor for cognitive impairment in $\mathrm{CCH}[7,9,10]$, with $\mathrm{CCH}$ patients often suffering long-term neurological deficits and cognitive impairment in the process of cerebral hypoperfusion [2]. Indeed, a previous study indicated that patients with vascular cognitive impairment exhibited typical neuron loss [11]. Identifying promising strategies for reducing neuronal death is paramount for long-term functional improvement in $\mathrm{CCH}$ patients.

\section{$\mathrm{CCH}$ does not influence acute neural cell death but can induce a chronic phase of neuronal} degeneration, death, and loss. Chronic cerebral ischemia and neural death are accompanied by longlasting neuroinflammation. Chronic neuroinflammation is tightly related to neuronal death [5], suggesting that reducing neuronal death could be a promising therapeutic opportunity for improving the neurological outcomes of $\mathrm{CCH}$.

Microglia are innate immune cells of the central nervous system and are the major mediators of neuroinflammation, microglia can be activated to polarize after stimulation, which exerts proinflammatory or anti-inflammatory functions through the secretion different substances [12] . 
Neuroinflammation has been linked strongly to cognitive deficits, activated (proinflammatory) microglia can reduce new cell survival and may also affect their integration into pre-existing neural networks [13]. Activated microglia can have M1 and M2 phenotypes: M1 microglia are proinflammatory and secrete inflammatory cytokines that promote neuronal damage under pathological conditions, while M2 microglia express anti-inflammatory mediators that prevent inflammation and contribute to neurological protection [14].

In our previous study, we reported that the $\mathrm{CCH}$ process can lead to activation of microglia in the brain [7]. Indeed, mounting evidence has demonstrated that the microglia with the antiinflammatory phenotype play a neurorestorative role during the recovery period after ischemic events [8]. However, the process of cerebral microglial polarization in $\mathrm{CCH}$ is not clear. Hippocampal microglial polarization was shown to be associated with the M1 phenotype during $\mathrm{CCH}$ [12], and therefore, regulating the polarization of microglia in the brain may be a novel therapeutic target for neurological recovery after $\mathrm{CCH}$.

Adiponectin (APN) is mainly secreted by mature adipocytes and can function as an insulinsensitizing adipokine, with a globular domain that acts as its functional region [15]. APN is the main adipokine controlling the balance of energy metabolism at both cellular and systemic levels [16], and APN is considered a biomarker for metabolic diseases in multiple systemic systems because it has significant antiatherosclerotic, antiapoptotic, organ-protective, anti-inflammatory, and other biological functions [15]. APN and its receptor are expressed in the central nervous system of mammals; additionally, peripheral APN can enter the cerebrospinal fluid through blood circulation [17]. Recent studies [13, 17-19] have shown that APN is closely associated with neurological diseases and that APN has neuroprotective effects. A clinical study has shown that APN levels $<4 \mu \mathrm{g} / \mathrm{mL}$ is independently 
associated with mortality, and low plasma APN is related to an increased risk of 5-year mortality after first-ever ischemic stroke [20]. The reduction of APN levels can weaken anti-inflammatory capacity and increase susceptibility to the ischemic vascular disease progression $[17,18]$. In the serum of elderly patients with type 2 diabetes, APN levels are decreased, and this is closely related to the outcome of neurocognitive impairment [19]. Moreover, as a biomarker that represent one of the inflammation, APN can be used as a marker in patients with clinical cognitive impairment [13]; however, the exhaustive effects of APN on and neuroinflammation microglial polarization following $\mathrm{CCH}$ are not well elucidated. Furthermore, due to the limited blood-brain barrier penetrability of the full length APN, adenovirus-mediated and intracerebroventricular injection for APN supplementation may be traumatic and unsuitable for clinical practice. According to the amino acid sequence of the functional globular domain at the C-terminal end of APN, a variant APN peptide (APN-P) that can effectively cross the blood-brain barrier was used in this study [16, 21]. Antibody microarray experiments are used as the initial tool during the biomarker discovery process [22]. In this study, using antibody microarray, we showed that the APN protein levels decreased in the cortex 12 weeks after $\mathrm{CCH}$. A better understanding of the interactions between microglial polarization and APN might provide new therapeutic targets for the treatment of $\mathrm{CCH}$. To address this challenge, we attempted to explore the role and underlying mechanisms of two subtypes of activated microglia-mediated neuroinflammation, as well as the interactions between microglial polarization and neuronal death in $\mathrm{CCH}$, with or without APN-P treatment. 
A total of 138 eight-week-old healthy, adult male Sprague-Dawley rats weighing 200-250 g were obtained from the Laboratory Animal Center of Fourth Military Medical University. All rats were housed in a specific pathogen-free animal room at a constant temperature $\left(23^{\circ} \mathrm{C} \pm 1^{\circ} \mathrm{C}\right)$ and humidity $(60 \% \pm 10 \%)$ in a 12-h light/dark cycle. The rats were conditioned for 4 weeks before the experiments started and given free access to food and water. All animal experimental procedures were approved by the Ethics Committee for Animal Experimentation of the Xi'an Jiaotong University, and followed the National Institutes of Health Guide for the Care and Use of Laboratory Animals [12].

\section{Animal surgery}

Rats were anesthetized with $3 \%$ sodium pentobarbital [50 mg/kg, intraperitoneal (i.p.) injection]. Rats were subjected to permanent bilateral common carotid artery occlusion (BCCAO) surgery to induce $\mathrm{CCH}$ as described previously $[2,7,12]$. Briefly, both common carotid arteries were ligated with two 4-0 sutures. Sham rats underwent bilateral common carotid artery exposure but not artery occlusion.

\section{Cell cultures}

The mouse microglia cell line BV2 and mouse hippocampal neuronal cell line HT-22 were purchased from the China Center for Type Culture Collection. BV2 and HT-22 cells were cultured in high-glucose Dulbecco's modified Eagle medium (DMEM, Hyclone, USA), supplemented with 10\% fetal bovine serum (Gibco, USA) and 1\% penicillin-streptomycin solution (Gibco, USA). Cells were incubated in $5 \% \mathrm{CO}_{2}$ humidified atmosphere at $37^{\circ} \mathrm{C}$. BV2 and $\mathrm{HT}-22$ cells were seeded into 
6-well plates at a density of $2 \times 10^{5}$ cells $/ \mathrm{mL}$. Primary neuronal cultures were harvested from the cerebral cortices of E16-E18 mouse embryos. Poly-D-lysine-coated culture plates or glass cover slips were prepared, then dissociated cells were obtained and seeded. The neurobasal medium (Gibco, USA) contained 2\% B27 (Invitrogen, USA) and 1\% penicillin and streptomycin. Primary cortical neurons were seeded in 6-well plates at a density of $4 \times 10^{5}$ cells $/ \mathrm{mL}$.

\section{Drug administration}

The synthetic peptide amino acid sequence of the recombinant APN-P is $\mathrm{NH}_{2}$ LQVYGDGDHNGLYADNVN-COOH [23] (Fig. 2a). For in vivo experiments, APN-P was dissolved in a $0.9 \%$ saline solution and administered to rats in the treatment group through every other day tail vein injections of $1 \mathrm{mg} / \mathrm{kg}$ APN-P immediately after BCCAO induction.

For in vitro experiments, we used $200 \mathrm{ng} / \mathrm{mL}$ lipopolysaccharide (LPS) (Sigma, USA) for $24 \mathrm{~h}$ to identify inflammatory responses in BV2 cells. APN-P was added to the medium $2 \mathrm{~h}$ before the addition of LPS. APN-P solutions at concentrations of $25 \mu \mathrm{M}, 50 \mu \mathrm{M}$, and $100 \mu \mathrm{M}$ were prepared, and $50 \mu \mathrm{M}$ was selected for further experiments.

\section{Experimental Design}

Experiment 1. Differential expression analysis of cortical proteins in $\mathrm{CCH}$ rats using antibody

173 microarrays. Fresh frozen cortex tissue was analyzed using antibody-based protein microarrays (sham group: $\mathrm{n}=6$; $\mathrm{CCH} 12 \mathrm{w}$ group: $\mathrm{n}=6$ ). A commercially available microarray (Biotin labelbased rat antibody array, AAR-BLG-1, RayBiotech $\AA$, United States) was used, which included 90 antibodies made up of 16 classifications that included cytokines, neurokines, and chemokines, as 
well as another 12 control antibodies. A detailed manufacturer's protocol was described in previous reports $[7,24]$.

\section{Experiment 2: Neuroprotective effects of APN-P on microglial polarization induced by $\mathrm{CCH}$}

and exploration of the underlying mechanisms in vivo. In total, 138 rats (27 rats in the sham group; 111 out of an initial 121 rats survived $\mathrm{CCH}$ surgery) were randomly and evenly divided into the sham, $\mathrm{CCH}[\mathrm{CCH} 4$ weeks (w) (4w after BCCAO surgery), $\mathrm{CCH} 8 \mathrm{w}, \mathrm{CCH} 12 \mathrm{w}]$, and $\mathrm{CCH}+\mathrm{APN}-\mathrm{P}(\mathrm{CCH} 4 \mathrm{w}+\mathrm{APN}-\mathrm{P}, \mathrm{CCH} 8 \mathrm{w}+\mathrm{APN}-\mathrm{P}, \mathrm{CCH} \quad 12 \mathrm{w}+\mathrm{APN}-\mathrm{P})$ treatment groups (1 $\mathrm{mg} / \mathrm{kg} / \mathrm{Qod})$. After the CCH or intervention with APN-P, rats were tested for behavioral function using a water maze test, and were then sacrificed to evaluate immunofluorescence staining, neuronal morphology, western blotting and quantitative real-time PCR (qRT-PCR) analyses. Animal groups and the number of rats used in the study are shown in Additional file 1. Rats were euthanized by sodium pentobarbital overdose [100 $\mathrm{mg} / \mathrm{kg}$, intraperitoneal (i.p.) injection] at the corresponding experimental end points.

\section{Experiment 3: Exploration of the mechanism of the protective role of APN-P in vitro. BV2 cells} were cultured in a different type of dishes to approximately $80 \%$ confluence before intervention. The groups and interventions included: (1) control group: with conventional medium; (2) APN-P group: addition of $50 \mu \mathrm{M}$ APN-P for $26 \mathrm{~h}$ in total; (3) LPS group: addition of $200 \mathrm{ng} / \mathrm{mL}$ LPS for $24 \mathrm{~h}$ in total; (4) LPS+BAY 11-7082 (BAY) group: we treated the cells with a known potent inhibitor of NF-kB, BAY $(10 \mu \mathrm{M})$ for 30 min prior to stimulating the BV2 cells with LPS, then plus 200 $\mathrm{ng} / \mathrm{mL}$ LPS for another $24 \mathrm{~h}$; and (5) LPS+APN-P group: addition of $50 \mu \mathrm{M}$ APN-P for $2 \mathrm{~h}$ prior to 
stimulating the BV2 cells with LPS, then plus $200 \mathrm{ng} / \mathrm{mL}$ LPS for another $24 \mathrm{~h}$.

Morris water maze test

Learning and spatial memory in the rats from different groups were evaluated with the Morris water maze test 4,8 , and 12 weeks after BCCAO using a previously described method [7]. The mean escape latency (EL) of four training sessions was recorded as a daily learning score from the $1^{\text {st }}$ to $5^{\text {th }}$ day. The swimming path and number of times that the rats crossed the platform in $60 \mathrm{~s}$ on the $6^{\text {th }}$ day were recorded as the score for spatial memory by the animal behavioral recording system.

Microglia-neuron co-cultures

HT-22 cells were plated into 24 -well plates $\left(2 \times 10^{4}\right.$ cells $\left./ \mathrm{mL}\right)$. BV2 cells were divided into the five groups as above in $0.4-\mu \mathrm{m}$ pore-sized Transwell inserts (Costar, USA) $\left.\left(1 \times 10^{4} \mathrm{cells} / \mathrm{mL}\right)\right)$. Thereafter, Transwell inserts and the medium from each group of BV2 cells was respectively collected and transferred to HT-22 cells for another $48 \mathrm{~h}$. The HT22 cell viability was measured by the intensity of 5-chloromethylfluorescein diacetate (CMFDA) fluorescence to determine the effects of the secreted cytokines from each groups of BV2 cells. For the indirect microglia-neuron co-cultures, primary cortical neurons were plated into 24-well plates $\left(8 \times 10^{4}\right.$ cells $\left./ \mathrm{mL}\right)$ and incubated for $3 \mathrm{~d}$. BV2 microglia were then added to $0.4-\mu \mathrm{m}$ poresized Transwell inserts (Costar, USA) $\left(1 \times 10^{4}\right.$ cells $\left./ \mathrm{mL}\right)$. After treatment, Transwell inserts and the medium from each group of BV2 cells was respectively collected and transferred, and the neurons and BV2 microglia were co-cultured for another $3 \mathrm{~d}$. The viability of primary cortical neurons were measured via CCK-8 test. 


\section{Nissl staining}

223 Nissl staining was used to observe morphological changes in neurons within the cortex of $\mathrm{CCH}$ rats.

224 Rats were transcardially perfused (chest ribs were dissected to expose heart tissue for perfusion)

225 with physiological saline solution followed by 4\% paraformaldehyde [25] and following the manufacturer's instruction of the Nissl staining kit (E607316, Sangon Biotech, China). Neurons in three different fields were counted. Intact neurons were shown as a rich cytoplasm, one or two large round nuclei with large cell bodies, but damaged neurons were shown as dark cytoplasm, condensed nuclei, empty vesicles or shrunken cell bodies.

\section{Immunofluorescence staining}

In vivo experiments. The selected brain slices were incubated with phosphate-buffered saline (PBS)

solution with $0.1 \%$ Triton X-100 for 30 min, then blocked with PBS containing 5\% goat serum

(Gibco, USA) for another $30 \mathrm{~min}$. The samples were incubated overnight at $4{ }^{\circ} \mathrm{C}$ with the following primary antibodies: anti-Iba-1 (1:200; Abcam), anti-APN (1:200; Abcam), anti-CD16 (1:200; Abcam), anti-CD206 (1:200; Abcam), anti-NeuN (1:200; Abcam). The sections were rinsed in PBS and incubated with the corresponding secondary antibodies (Abcam) for $1 \mathrm{~h}$ at $25^{\circ} \mathrm{C}$. Lastly, sections were incubated in 4,6-diamidino-2-phenylindole (DAPI) solution (Invitrogen, USA) for $15 \mathrm{~min}$ at $25^{\circ} \mathrm{C}$. All section images were blindly captured using a fluorescence microscope (Nikon, Japan) and analyzed with the Image J software.

In vitro experiments. BV2 cells were fixed with $4 \%$ formaldehyde solution, incubated with $0.1 \%$ 
$30 \mathrm{~min}$. The samples were incubated overnight at $4{ }^{\circ} \mathrm{C}$ with the following primary antibodies: anti-

Iba-1 (1:200, Abcam), anti-CD16 (1:200, Abcam), anti-CD206 (1:200, Abcam). The appropriate secondary antibodies (Abcam) were used, and the nuclei were stained with DAPI (Invitrogen, USA).

Sample images were captured with a fluorescence microscope (Nikon, Japan) and analyzed with the Image J software.

\section{Western blotting}

The selected samples were collected and homogenized in ice-cold RIPA buffer with $1 \%$ protease and phosphatase inhibitors, with an ultrasonic homogenizer. The lysates were centrifuged, then the supernatants were transferred to new frozen storage tubes (stored at $-80^{\circ} \mathrm{C}$ ). Protein concentrations were measured with a BCA Protein Assay kit (Thermo Fisher Scientific, USA). Protein samples were separated with SDS-PAGE, with $20 \mu \mathrm{g}$ protein loaded into each well of the electrophoresis gels. The proteins were then transferred to PVDF membranes (Millipore, USA). Membranes were blocked with 5\% non-fat milk in TBST and then incubated with primary antibodies overnight at $4^{\circ} \mathrm{C}$, then each membranes were incubated with the appropriate secondary antibodies (1:5000, Abcam) at room temperature for another $2 \mathrm{~h}$. After washing three times for $5 \mathrm{~min}$ in TBST, the protein bands were detected using a Bio-Rad Imaging System (Bio-Rad, USA). The following primary antibodies were used: anti-APN (1:800, Abcam); anti-iNOS (1:1000, Abcam); anti- 
Cortex tissue of rats and BV2 cells were collected from each treatment groups. Total RNA was isolated using an RNA Extraction Kit (Thermo Fisher Scientific, USA) and quantified. Then, reverse

267 transcription using a reverse transcriptase kit (TaKaRa, Japan). Real-time PCR was performed 268 according to the manufacturer's manual for SYBR green (TaKaRa, Japan). The reaction was 269 performed at $95^{\circ} \mathrm{C}$ for $3 \mathrm{~min}$ followed by 40 cycles of $95^{\circ} \mathrm{C}$ for $10 \mathrm{~s}$ and $55^{\circ} \mathrm{C}$ for $30 \mathrm{~s}$ on the Bio270 Rad PCR Detection System (Bio-Rad, USA). The primers (Table 1) and sequences derived from 271 the relative mRNA expression levels were calculated using the $2^{-\Delta \Delta \mathrm{CT}}$ method and the data were 272 presented normalized by $\beta$-actin.

274 Table 1 Primers used for qRT-PCR

\begin{tabular}{|c|c|c|c|}
\hline Primers & species & Forward (5'-3') & Reverse (5'-3') \\
\hline iNOS & Rat & TTCACGACACCCTTCACCACA & TCTCTGGGTCCTCTGGTCAAAC \\
\hline & Mice & CAACAGGAACCTACCAGCTCACT & AGCCTGAAGTCATGTTTGCCG \\
\hline IL-6 & Rat & AAGAGACTTCCAGCCAGTTGCC & TGTGGGTGGTATCCTCTGTGAAG \\
\hline IL-18 & Mice & TTCTTGGGACTGATGCTGGTG & GCCATTGCACAACTCTTTTCTC \\
\hline & Mice & GGAATCAGACCACTTTGGCAGA & GTCTGGTCTGGGATTCGTTGG \\
\hline IL-1 $\beta$ & Rat & AATGGACAGAACATAAGCCAACA & CTTCTTCTTTGGGTATTGTTTGG \\
\hline & Mice & TGCCACCTTTTGACAGTGATG & TGATGTGCTGCTGCGAGATT \\
\hline TNF- $\alpha$ & Rat & CCAGGTTCTCTTCAAGGGACAA & GGTATGAAATGGCAAATCGGCT \\
\hline & Mice & CCCTCACACTCACAAACCACC & CTTTGAGATCCATGCCGTTG \\
\hline Arg-1 & Rat & CACCTGAGTTTTGATGTTGATGG & CTCTGGCTTATGATTACCTTCCC \\
\hline & Mice & GGTGGCAGAGGTCCAGAAGAA & CCCATGCAGATTCCCAGAGC \\
\hline IL-10 & Rat & GCACTGCTATGTTGCCTGCTC & CCCAAGTAACCCTTAAAGTCCTG \\
\hline & Mice & TTTAAGGGTTACTTGGGTTGCC & AATGCTCCTTGATTTCTGGGC \\
\hline TGF- $\beta$ & Rat & CCAACTACTGCTTCAGCTCCACA & GCTTGCGACCCACGTAGTAGA \\
\hline$\beta-$ actin & Mice & CAACAATTCCTGGCGTTACCT & GCCCTGTATTCCGTCTCCTT \\
\hline & Mice & TGCTATGTTGCCCTAGACTTCG & GTTGGCATAGAGGTCTTTACGG \\
\hline & GTACGTTGACATCCGTAAAGA & GTAACAGTCCGCCTAGAAGCAC \\
\hline
\end{tabular}


Cell Counting Kit-8 (CCK-8) (Dojindo, Japan) was used to assess primary neuron viability. The protocol was performed according to the manufacturer's manual. Briefly, in each 96-well plate, 10 $\mu \mathrm{L}$ CCK-8 solution was added to $90 \mu \mathrm{L}$ medium solution and incubated for $4 \mathrm{~h}$ at $37^{\circ} \mathrm{C}$. The absorbance at $450 \mathrm{~nm}$ was measured with a microplate reader (Thermo Fisher Scientific, USA).

\section{CMFDA labeling}

HT-22 cells were labeled with CMFDA ( $1 \mu \mathrm{M}$; C2925; Invitrogen) before initiating the co-culture with BV2 cells in different treatment groups. The experimental steps were performed according to the manufacturer's manual. Briefly, HT22 cells were cultured in a medium containing $1 \mu \mathrm{M}$ CMFDA for 30 min then co-cultured with BV2 cells.

\section{Statistical analyses}

Data sets were analyzed using SPSS version 19.0 software (SPSS Inc., Chicago, IL). All values are expressed as the mean $\pm \mathrm{SD}$ and are indicated in the figure legends. The statistical analysis was performed by comparing the means of two groups using an unpaired two-tailed Student's t-test. For multiple comparisons, the data were analyzed by One-way ANOVA with Tukey's multiple comparison test. Assessment of MWM results were analyzed by Two-way ANOVA with Bonferroni post hoc test. Statistical significance was considered at $\mathrm{p}<0.05$.

\section{Results}


model for $\mathrm{CCH}$ using BCCAO surgery. First, we evaluated the polarization of microglia in rats at 2 ,

4, 8 and 12 weeks after BCCAO surgery. Immunofluorescence staining showed that the number cells in the cortex region that were positive for the microglial marker Iba-1 (Iba-1+ cells) significantly increased at 4 weeks and gradually increased at 8 and 12 weeks after BCCAO surgery [sham vs. $\mathrm{CCH} 2 \mathrm{w}(\mathrm{F}=0.43, \mathrm{P}>0.05)$; sham vs. $\mathrm{CCH} 4 \mathrm{w}(\mathrm{F}=0.00, \mathrm{P}<0.01)$; sham vs. $\mathrm{CCH}$ $8 \mathrm{w}(\mathrm{F}=1.93, \mathrm{P}<0.01)$; sham vs. $\mathrm{CCH} 12 \mathrm{w}(\mathrm{F}=4.50, \mathrm{P}<0.01)]$. Moreover, visualization of the microglial morphologies indicated that $\mathrm{CCH}$ promoted microglia activation and neuroinflammation (Fig. 1b-c). Spearman correlation analysis showed a negative correlation between the number of Iba- $1+$ and $\mathrm{NeuN}+$ cells $[\mathrm{CCH} 2 \mathrm{w}$ (correlation coefficient $=-0.977, \mathrm{P}=$ 0.023); $\mathrm{CCH} 4 \mathrm{w}$ (correlation coefficient $=-0.961, \mathrm{P}=0.039)$; $\mathrm{CCH} 8 \mathrm{w}$ (correlation coefficient $=$ 0.962, $\mathrm{P}=0.038$ ); $\mathrm{CCH} 12 \mathrm{w}$ (correlation coefficient $=-0.964, \mathrm{P}=0.036)]($ Fig. 1d). Therefore, $\mathrm{CCH}$ induced microglial activation, which was accompanied by neuronal damage in the cortex. significantly decreased in cortex of the $\mathrm{CCH}$ rats $(\mathrm{CCH} 12 \mathrm{w})$ compared to the sham rats (Fold change: -4.23; $\mathrm{P}<0.05)$ (Fig. 1e).

Double immunofluorescence staining showed that the percentage of APN-positive microglial $(\mathrm{APN}+\mathrm{Iba}-1+)$-cells in the cortex significantly decreased in the $12^{\text {th }}$ week after $\mathrm{CCH}$ compared to the $\operatorname{sham}(27.11 \% \pm 1.89$ vs. $80.83 \% \pm 5.59, \mathrm{~F}=10.36, \mathrm{P}<0.01)$ (Fig. 1f-g). 
administration of APN-P (Fig. 2b), APN expression was upregulated [(F $=236.27$, $\mathrm{CCH} 4 \mathrm{w}$ vs.

322 sham, $\mathrm{P}<0.01 ; \mathrm{CCH} 4 \mathrm{w}$ vs. $\mathrm{CCH} 4 \mathrm{w}+\mathrm{APN}-\mathrm{P}, \mathrm{P}<0.01),(\mathrm{F}=196.42$, $\mathrm{CCH} 8 \mathrm{w}$ vs. sham, $\mathrm{P}$

$323<0.01 ; \mathrm{CCH} 8 \mathrm{w}$ vs. $\mathrm{CCH} 8 \mathrm{w}+\mathrm{APN}-\mathrm{P}, \mathrm{P}<0.01),(\mathrm{F}=271.02, \mathrm{CCH} 12 \mathrm{w}$ vs. sham, $\mathrm{P}<0.01 ;$

$324 \mathrm{CCH} 12 \mathrm{w}$ vs. $\mathrm{CCH} 12 \mathrm{w}+\mathrm{APN}-\mathrm{P}, \mathrm{P}<0.01)$ ] (Fig. 2b-c). In addition, $\mathrm{CCH}$ increased the relative

325 intensity (relative level) of iNOS (M1 marker), while APN-P treatment decreased the protein

326 expression of iNOS $[(\mathrm{F}=398.00, \mathrm{CCH} 4 \mathrm{w}$ vs. sham, $\mathrm{P}<0.01 ; \mathrm{CCH} 4 \mathrm{w}$ vs. $\mathrm{CCH} 4 \mathrm{w}+\mathrm{APN}-\mathrm{P}, \mathrm{P}$

$327<0.01),(\mathrm{F}=415.82, \mathrm{CCH} 8 \mathrm{w}$ vs. sham, $\mathrm{P}<0.01 ; \mathrm{CCH} 8 \mathrm{w}$ vs. $\mathrm{CCH} 8 \mathrm{w}+\mathrm{APN}-\mathrm{P}, \mathrm{P}<0.01)$,

$328(\mathrm{~F}=702.77, \mathrm{CCH} 12 \mathrm{w}$ vs. sham, $\mathrm{P}<0.01 ; \mathrm{CCH} 12 \mathrm{w}$ vs. $\mathrm{CCH} 12 \mathrm{w}+\mathrm{APN}-\mathrm{P}, \mathrm{P}<0.01)]$. While

$329 \mathrm{CCH}$ decreased in the expression of Arg-1 (M2 marker), this expression was rescued by APN-P

330 treatment in the $\mathrm{CCH}$ treatment group $[(\mathrm{F}=22.30, \mathrm{CCH} 4 \mathrm{w}$ vs. sham, $\mathrm{P}<0.01 ; \mathrm{CCH} 4 \mathrm{w}$ vs. $\mathrm{CCH}$

$3314 \mathrm{w}+\mathrm{APN}-\mathrm{P}, \mathrm{P}<0.01),(\mathrm{F}=223.22, \mathrm{CCH} 8 \mathrm{w}$ vs. sham, $\mathrm{P}<0.01 ; \mathrm{CCH} 8 \mathrm{w}$ vs. $\mathrm{CCH} 8 \mathrm{w}+\mathrm{APN}-$

$332 \mathrm{P}, \mathrm{P}<0.01),(\mathrm{F}=204.98, \mathrm{CCH} 12 \mathrm{w}$ vs. sham, $\mathrm{P}<0.01 ; \mathrm{CCH} 12 \mathrm{w}$ vs. $\mathrm{CCH} 12 \mathrm{w}+\mathrm{APN}-\mathrm{P}, \mathrm{P}$

$333<0.01)]($ Fig. 2b-c) .

334 Using double-immunofluorescence staining, the co-localization of the M1-associated marker CD16

335 or the M2-associated marker CD206 with Iba-1 was quantified (Fig. 2d-e). To clarify the

336 characteristic activated microglia phenotype, the numbers of CD16-positive (CD16+) and CD206-

337 positive $(\mathrm{CD} 206+)$ microglia cells were analyzed, respectively. Compared to the sham group, the

338 number of positive Iba-1+ cells and both microglia phenotypes gradually increased in the cortex of

$339 \mathrm{CCH}$ rats from the $4^{\text {th }}$ to $12^{\text {th }}$ week, especially the number of CD16+ microglia (Fig. $\left.2 \mathbf{d}-\mathbf{h}\right)$.

340 Compared to the $\mathrm{CCH}$ rats, APN-P treatment relieved microglia activation (neuroinflammation)

341 according to the number of positive Iba- $1+$ cells $[(\mathrm{F}=96.10, \mathrm{CCH} 4 \mathrm{w}$ vs. sham, $\mathrm{P}<0.01 ; \mathrm{CCH}$

$3424 \mathrm{w}$ vs. $\mathrm{CCH} 4 \mathrm{w}+\mathrm{APN}-\mathrm{P}, \mathrm{P}<0.01),(\mathrm{F}=234.43, \mathrm{CCH} 8 \mathrm{w}$ vs. sham, $\mathrm{P}<0.01 ; \mathrm{CCH} 8 \mathrm{w}$ vs. 
$\mathrm{CCH} 8 \mathrm{w}+\mathrm{APN}-\mathrm{P}, \mathrm{P}<0.01),(\mathrm{F}=300.24, \mathrm{CCH} 12 \mathrm{w}$ vs. sham, $\mathrm{P}<0.01 ; \mathrm{CCH} 12 \mathrm{w}$ vs. $\mathrm{CCH}$

344 12w +APN-P, P $<0.01)$ ] and the microglial morphologies (Fig. 2d-f). Furthermore, we observed

345 that APN-P treatment decreased the number of CD16+ microglia cells $[(\mathrm{F}=118.48, \mathrm{CCH} 4 \mathrm{w}$ vs.

346 sham, $\mathrm{P}<0.01 ; \mathrm{CCH} 4 \mathrm{w}$ vs. $\mathrm{CCH} 4 \mathrm{w}+\mathrm{APN}-\mathrm{P}, \mathrm{P}<0.01),(\mathrm{F}=521.70, \mathrm{CCH} 8 \mathrm{w}$ vs. sham, $\mathrm{P}$

$347<0.01 ; \mathrm{CCH} 8 \mathrm{w}$ vs. $\mathrm{CCH} 8 \mathrm{w}+\mathrm{APN}-\mathrm{P}, \mathrm{P}<0.01),(\mathrm{F}=151.54, \mathrm{CCH} 12 \mathrm{w}$ vs. sham, $\mathrm{P}<0.01 ;$

$348 \mathrm{CCH} 12 \mathrm{w}$ vs. CCH 12w +APN-P, P $<0.01)]$ and increased the number of CD206+ microglia cells

$349[(\mathrm{~F}=84.45, \mathrm{CCH} 4 \mathrm{w}$ vs. sham, $\mathrm{P}<0.01 ; \mathrm{CCH} 4 \mathrm{w}$ vs. $\mathrm{CCH} 4 \mathrm{w}+\mathrm{APN}-\mathrm{P}, \mathrm{P}<0.01),(\mathrm{F}=330.95$,

$350 \mathrm{CCH} 8 \mathrm{w}$ vs. sham, $\mathrm{P}<0.01 ; \mathrm{CCH} 8 \mathrm{w}$ vs. $\mathrm{CCH} 8 \mathrm{w}+\mathrm{APN}-\mathrm{P}, \mathrm{P}<0.01),(\mathrm{F}=377.84, \mathrm{CCH} 12 \mathrm{w}$

351 vs. sham, $\mathrm{P}<0.01 ; \mathrm{CCH} 12 \mathrm{w}$ vs. CCH $12 \mathrm{w}+\mathrm{APN}-\mathrm{P}, \mathrm{P}<0.01)]$ (Fig. 2d, e, g, h). Subsequently,

352 the ratio of CD16/CD206 and CD206/CD16 were statistically analyzed to better understand the

353 dynamic changes in microglial polarization. A ratio of CD16/CD206 higher than 1 indicates

354 microglial polarization toward the M1 phenotype, while a ratio of CD206/CD16 higher than 1

355 indicates microglial polarization toward the M2 phenotype [12]. The data showed that the

356 CD16/CD206 ratio increased 4 weeks after $\mathrm{CCH}$ and reached its highest value at 12 weeks

357 compared to the sham condition [CCH 4w vs. sham, $2.94 \pm 0.91$ vs. $1.08 \pm 0.14, \mathrm{P}=0.013 ; \mathrm{CCH} 8 \mathrm{w}$

358 vs. sham, $3.93 \pm 0.53$ vs. $1.08 \pm 0.14, \mathrm{P}<0.01 ; \mathrm{CCH} 12 \mathrm{w}$ vs. sham, $4.89 \pm 0.72$ vs. $1.08 \pm 0.14, \mathrm{P}<$

359 0.01] (Fig. 2i). However, CCH rats that received APN-P treatment had an increased CD206/CD16

360 ratio compared to $\mathrm{CCH}$ rats that did not receive APN-P [CCH 4w $+\mathrm{APN}-\mathrm{P}$ vs. $\mathrm{CCH} 4 \mathrm{w}, 2.00 \pm 0.50$

361 vs. $0.33 \pm 0.07, \mathrm{P}<0.01 ; \mathrm{CCH} 8 \mathrm{w}+\mathrm{APN}-\mathrm{P}$ vs. $\mathrm{CCH} 8 \mathrm{w}, 3.67 \pm 0.29$ vs. $0.26 \pm 0.03, \mathrm{P}<0.01$;

$362 \mathrm{CCH} 12 \mathrm{w}+\mathrm{APN}-\mathrm{P}$ vs. $\mathrm{CCH} 12 \mathrm{w}, 3.17 \pm 0.29$ vs. $0.21 \pm 0.03, \mathrm{P}<0.01]$ (Fig. 2j).

363 To further verify that microglial polarization was associated with the M1 or M2 phenotype after

364 CCH or APN-P treatment, qRT-PCR analysis was performed using different microglial markers to 
assess the status of the M1 and M2 phenotypes. We found that APN-P treatment significantly reversed the CCH-induced upregulation of inflammatory cytokines (iNOS, $I L-6, I L-18, I L-1 \beta$, and $T N F-\alpha)[(i N O S, \mathrm{P}<0.01),(I L-6, \mathrm{P}<0.01),(I L-18, \mathrm{P}<0.01),(I L-1 \beta, \mathrm{P}<0.01),(T N F-\alpha$, $\mathrm{P}<0.01)]$ (Fig. 3a-e) and the downregulation of anti-inflammatory cytokines (Arg-1, IL-10, and $T G F-\beta)[(\operatorname{Arg}-1, \mathrm{P}<0.01),(I L-10, \mathrm{P}<0.01),(T G F-\beta, \mathrm{P}<0.01)]$ in cortex $($ Fig. 3f-h $)$.

These results suggested that $\mathrm{CCH}$ induced microglial polarization toward the M1 phenotype, while APN-P treatment induced microglial polarization toward the M2 phenotype.

LPS is a strong stimulator of microglial activation, BV2 cells activated by LPS can act as an in vitro neuroinflammation model (LPS-BV2 cells) [26]. Using this model, the co-localization of the M1associated marker CD16 or the M2-associated marker CD206 with Iba-1 was assessed using doubleimmunofluorescence staining (Fig. 4a-b). Compared to the control group, the numbers of both microglial phenotypes gradually increased in the LPS stimulation group, especially those for CD16+ microglia $[\mathrm{F}=196.00$, Control vs. APN-P, P $>0.05$; Control vs. LPS, P $<0.01$; LPS vs. LPS+APN-P, P $<0.01]$. Conversely, APN-P treatment decreased the number of CD16+ microglia but increased the number of CD206 + microglia when compared to the control group $[\mathrm{F}=232.87$, Control vs. APN-P, P $<$ 0.01; Control vs. LPS, P=0.087; LPS vs. LPS+APN-P, P $<0.01]$ (Fig. 4c-d). In addition, the ratio of CD16/CD206 was higher than 1 in the LPS-stimulated BV2 cells [F $=121.17$, Control vs. APN-P, $0.54 \pm 0.04$ vs. $0.32 \pm 0.03, \mathrm{P}>0.05$; Control vs. LPS, $0.54 \pm 0.04$ vs. $2.97 \pm 0.38, \mathrm{P}<0.01 ;$ LPS vs. LPS + APN-P, $2.97 \pm 0.38$ vs. $0.70 \pm 0.04, \mathrm{P}<0.01]$ (Fig. 4e), while the CD206/CD16 ratio was higher than 1 in the APN-P-treated LPS-BV2 cells $[\mathrm{F}=107.99$, Control vs. APN-P, $1.86 \pm 0.16$ vs. $3.11 \pm 0.03, \mathrm{P}<0.01$; Control vs. LPS, $1.86 \pm 0.16$ vs. $0.34 \pm 0.04, \mathrm{P}<$ 0.01; LPS vs. LPS+APN-P, $0.34 \pm 0.04$ vs. $1.43 \pm 0.07, \mathrm{P}<0.01]$ (Fig. 4 f). These results also 
indicated that APN-P treatment induced microglial polarization toward the M2 phenotype under environment of neuroinflammation in vitro.

APN-P promotes microglial polarization toward the M2 phenotype through inhibition of the

\section{NF-kB pathway}

We detected $\mathrm{p}-\mathrm{NF}-\mathrm{\kappa B}$ expression levels to further investigate whether the effect of APN-P on microglial polarization was mediated by NF- $\kappa \mathrm{B}$ pathway. The ratio of $\mathrm{p}-\mathrm{NF}-\kappa \mathrm{B} / \mathrm{NF}-\kappa \mathrm{B}$ significantly increased in the cortex of the $\mathrm{CCH}$ rats, while APN-P treatment significantly reduced this ratio [(F

$=68.66, \mathrm{CCH} 4 \mathrm{w}$ vs. sham, $\mathrm{P}<0.01 ; \mathrm{CCH} 4 \mathrm{w}$ vs. $\mathrm{CCH} 4 \mathrm{w}+\mathrm{APN}-\mathrm{P}, \mathrm{P}<0.01),(\mathrm{F}=307.90$,

$\mathrm{CCH} 8 \mathrm{w}$ vs. sham, $\mathrm{P}<0.01 ; \mathrm{CCH} 8 \mathrm{w}$ vs. $\mathrm{CCH} 8 \mathrm{w}+\mathrm{APN}-\mathrm{P}, \mathrm{P}<0.01),(\mathrm{F}=98.89, \mathrm{CCH} 12 \mathrm{w}$

vs. sham, $\mathrm{P}<0.01$; $\mathrm{CCH} 12 \mathrm{w}$ vs. $\mathrm{CCH} 12 \mathrm{w}+\mathrm{APN}-\mathrm{P}, \mathrm{P}<0.01)]$ (Fig. 5a-b). These results

APN-P treatment could inhibit the expression of $\mathrm{p}-\mathrm{NF}-\mathrm{kB}$ in LPS-activated BV2 cells $(\mathrm{F}=12.99$,

Control vs. LPS, $\mathrm{P}=0.015$; LPS vs. LPS+APN-P, $\mathrm{P}=0.049$ ), which was due to the effect of the $\mathrm{p}-$

NF- $\kappa B$ inhibitor, BAY in in the BV2 cells (LPS vs. LPS+BAY, P $<0.01)($ Fig. $\mathbf{5 c}-\mathbf{d})$. In addition,

Control vs. LPS, $\mathrm{P}<0.01$; LPS vs. LPS+BAY, $\mathrm{P}<0.01$; LPS vs. LPS+APN-P, $\mathrm{P}<0.01$ );

however, the M2 marker Arg-1 increased $(\mathrm{F}=46.39$, Control vs. LPS, $\mathrm{P}<0.01$; LPS vs.

LPS+BAY, $\mathrm{P}<0.01 ;$ LPS vs. LPS+APN-P, P = 0.037) with APN-P treatment in LPS-BV2 cells 
0.01)] (Fig. 5e-i), while that of anti-inflammatory factors $(\operatorname{Arg}-1, I L-10$, and $T G F-\beta)$ were increased

410 in both BAY- and APN-P-treated LPS-BV2 cells [(Arg-1, $\mathrm{P}<0.01),(I L-10, \mathrm{P}<0.01),(T G F-\beta$,

$411 \mathrm{P}<0.01)]($ Fig. $\mathbf{5 j}-\mathbf{m})$. These results indicated that APN-P promoted microglial polarization

412 toward the M2 phenotype through the inhibition of the NF-kB pathway.

The effects of APN-P on neuron protection in CCH rats and LPS-BV2 cells

415 When we used Nissl staining to evaluate neuron protection effect of APN-P, we found that compared

to the $\mathrm{CCH}$ group, APN-P treatment significantly alleviated neuron damage in the cortex $[\mathrm{CCH}$ 4w+APN-P vs. $\mathrm{CCH} 4 \mathrm{w}, \mathrm{F}=272.74, \mathrm{P}<0.01 ; \mathrm{CCH} 8 \mathrm{w}+\mathrm{APN}-\mathrm{P}$ vs. $\mathrm{CCH} 8 \mathrm{w}, \mathrm{F}=268.94, \mathrm{P}<$ 0.01; $\mathrm{CCH} 12 \mathrm{w}+\mathrm{APN}-\mathrm{P}$ vs. $\mathrm{CCH} 12 \mathrm{w}, \mathrm{F}=1080.41, \mathrm{P}<0.01]$ (Fig. 6a, b) and the CA1 region of the hippocampus [CCH 4w+APN-P vs. $\mathrm{CCH} 4 \mathrm{w}, \mathrm{F}=350.98, \mathrm{P}<0.01 ; \mathrm{CCH} 8 \mathrm{w}+\mathrm{APN}-\mathrm{P}$ vs. $\mathrm{CCH}$ 8w, $\mathrm{F}=126.90, \mathrm{P}<0.01 ; \mathrm{CCH} 12 \mathrm{w}+\mathrm{APN}-\mathrm{P}$ vs. $\mathrm{CCH} 12 \mathrm{w}, \mathrm{F}=282.12, \mathrm{P}<0.01]$ (Fig. 6a, c). These results indicated that APN-P treatment had neuroprotective effects against $\mathrm{CCH}$. To further determine whether the neuron protection effects of APN-P on microglia altered neuron viability in a neuroinflammation environment (i.e., LPS treatment), we constructed a microglia-neuron coculture system to mimic the coexistence of microglia cells and cortex/hippocampal neurons in vitro

(Fig. 6d). As shown in Fig. 6e, the viabilities of primary cortical neurons decreased in the LPStreated group, in which neurons were cultured by medium from LPS-treated BV2 cells. Indeed, in 427 groups treated with medium from LPS-treated BV2 cells supplemented with BAY and APN-P, neuron viability was significantly increased, although they did not return to normal levels $[\mathrm{F}=$ 
$\mathrm{P}<0.01]$. We further found that medium from LPS-treated BV2 cells supplemented with BAY and APN-P increased the number of CMFDA-positive hippocampal HT-22 cells, indicating improved cell viability in comparison to the LPS-treated BV2 cells $[\mathrm{F}=176.87$, Control vs. LPS, $154.43 \pm 2.03$ vs. $76.58 \pm 6.10, \mathrm{P}<0.01$; LPS+BAY vs. LPS, $149.54 \pm 4.31$ vs. $76.58 \pm 6.10, \mathrm{P}<$ 0.01; LPS+APN-P vs. LPS, $146.86 \pm 5.74$ vs. $76.58 \pm 6.10, \mathrm{P}<0.01]$ (Fig. 6f-g).

These results confirmed that in addition to reducing neuron death, APN-P supplementation could effectively decrease damage of primary cortical neurons and hippocampal HT-22 cell viability induced by LPS-BV2 cell neuroinflammation.

\section{APN-P improves learning and memory function in $\mathrm{CCH}$ rats}

Using the Morris water maze test, we showed that APN-P treatment improved learning, which was indicated by a decreased EL [(Day 1, F = 4.89, $\mathrm{P}>0.01),($ Day $2, \mathrm{~F}=12.99, \mathrm{P}<0.01),($ Day 3, $\mathrm{F}=75.66, \mathrm{P}<0.01),($ Day $4, \mathrm{~F}=84.68, \mathrm{P}<0.01),($ Day $5, \mathrm{~F}=73.09, \mathrm{P}<0.01)]($ Fig. 7a) and memory function, which was indicated by an increased frequency of platform crossing $(\mathrm{F}=$ 56.78, sham vs. $\mathrm{CCH}, \mathrm{P}<0.01, \mathrm{CCH}+\mathrm{APN}-\mathrm{P}$ vs. $\mathrm{CCH}, \mathrm{P}<0.01)$ and residence time in the target quadrant $(\mathrm{F}=84.99$, sham vs. $\mathrm{CCH}, \mathrm{P}<0.01, \mathrm{CCH}+\mathrm{APN}-\mathrm{P}$ vs. $\mathrm{CCH}, \mathrm{P}<0.01)$ compared to the $\mathrm{CCH}$ group (Fig. $\mathbf{b}-\mathbf{c})$. Representative images of frequency of platform crossing in different groups are displayed in Fig. 7d. These results indicated that APN-P treatment could improve cognitive function in $\mathrm{CCH}$ rats.

\section{Discussion}

$452 \mathrm{CCH}$ is a widespread condition observed in central nervous system diseases and commonly 
accompanied by cognitive impairment. Therefore, developing targeted therapeutic strategies to improve cognitive function are of great significance to the outcome of individuals with $\mathrm{CCH}$. The major findings of the present research can be summarized as follows: (a) $\mathrm{CCH}$ presents confounding pathological features including cognitive impairment, neuronal damage, microglial activation that mediates neuroinflammation, M1-type polarization, and exacerbated activation of NF-kB signaling. (b) APN-P treatment might be a novel therapeutic strategy for $\mathrm{CCH}$, evidenced by the increased neuronal survival and improved neurological function observed in $\mathrm{CCH}$ mice treated with APN-P when compared to the $\mathrm{CCH}$ control group. (c) APN-P treatment alleviated neuroinflammation and promoted microglia M2-type polarization after CCH and LPS stimulation. (d) Mechanistically, the positive APN-P effect on CCH-associated neuronal dysfunction and damage was NF-kB signalingdependent.

In addition to its known function in the maintenance of metabolic homoeostasis, APN possesses anti-inflammatory, antioxidant, and antiatherogenic properties [16]. The concentration of plasma APN declines is inversely correlated with poor outcomes of acute neural injury [16]. A previous report showed that APN protected against glutamate-induced excitotoxicity in nervous system-related diseases [27]. In an animal model for cerebral ischemia-reperfusion injury, APN attenuated oxidative stress and neuronal damage [17]. Additionally, APN ameliorated brain injury by suppressing astrocyte-derived inflammation following intracerebral hemorrhage [23]. Thus, there is considerable evidence that supports the direct and indirect influence of APN on $\beta$-amyloid and tau aggregate formation; thus, elevation of APN levels might constitute a neuroprotective strategy in AD [28]. APN is a classic anti-inflammatory agent in multiple systems including the cardio-cerebrovascular system via reducing inflammation and switching the macrophage phenotype 
to an anti-inflammatory state [15]. These studies suggest that reduced APN function plays a causative role in neurological impairment after $\mathrm{CCH}$, which inspired us to hypothesize that exogenous supplementation of APN could be a promising therapeutic strategy, although the role of $\mathrm{APN}$ in $\mathrm{CCH}$ is unclear.

Intracerebroventricular injection has been the primary method adopted for drug delivery [2]; however, this method can lead to cerebral injury and may not be suitable for clinical practice. Because the full-length APN has restricted blood-brain barrier permeability that reduces its potential for future clinical applications, a recombinant APN-P was synthetized [16, 23] and used in the present study. We found that APN-P significantly improved the cognitive function, attenuated microglial activation, and mediated neuroinflammation and neuronal survival in the rat cortex/hippocampus. These findings highlight the promising neuroprotective effects of APN-P treatment on $\mathrm{CCH}$ in human patients.

Previous study has suggested that neuroinflammation plays a crucial role in the cognitive dysfunction induced by $\mathrm{CCH}$ [29]. Microglia are resident immune cells of the central nervous system that maintain brain homeostasis. A previous study reported that neuroinflammation is mainly manifested by microglial activation and the subsequent release of inflammatory factors, which lead to brain damage ultimately [30]. In this study, we also found that microglia activation accompanied $\mathrm{CCH}$ in the cortex. Neuron death is a key hallmark of CCH-related cognitive impairment [7], and it is well established that inflammatory responses induced by $\mathrm{CCH}$, including the activation of glial cells and inflammatory cytokine production, could further result in neuron death and cognitive deficits [30]. In addition, we found that microglia activation was accompanied by neuronal damage in the cortex of $\mathrm{CCH}$ rats in this study. Therefore, inhibiting microglial activation to the pro- 
inflammatory phenotype could alleviate neuronal injury [29].

Activated microglia represent a variety of phenotypes after injury, including the broadly classified M1 and M2 phenotypes that are useful for understanding the function and effect of microglia in diversiform brain diseases [12]. The M2-to-M1 phenotypic changes during chronic inflammation may be regulated by a common pathologic mechanism that underlies multiple types of injuries in the central nervous system, including traumatic brain injury, white matter lesions, spinal cord injuries, and strokes [31]. These dynamic phenotypic changes observed in brain diseases suggest that manipulating microglial polarization might be a promising therapeutic strategy with neuroprotective effects. However, research on the underlying mechanism and related potential interventions of microglial polarization during $\mathrm{CCH}$ are currently limited. We used three methods to evaluate how $\mathrm{CCH}$ affects the microglial polarization process. First, we detected increased iNOS and decreased Arg-1 protein levels in the cortexes of $\mathrm{CCH}$ rats compared to sham controls. Second, immunofluorescence was used to evaluate Iba-1, CD16, and CD206 expression as biomarkers for microglial polarization. We found that the ratio of CD16/CD206 in Iba-1+ cells in the cortex of $\mathrm{CCH}$ rats gradually increased between 4 and 12 weeks after BCCAO surgery. Third, microglial polarization was further shown to significantly increase the mRNA levels of $i N O S, I L-6, I L-18, I L$ $1 \beta$, and $T N F-\alpha$ in $\mathrm{CCH}$ groups compared to those in the sham control. These results demonstrated that during $\mathrm{CCH}$, the microglia switched towards an M1 phenotype, which is associated with neuroinflammation. Conversely, APN-P treatment in $\mathrm{CCH}$ rats promoted the microglia towards the detrimental M2 phenotype, with decreased iNOS and increased Arg-1 expression, an increased CD206/CD16 ratio in Iba-1+ cells, and secretion of anti-inflammatory factors. 
reference memory is thought to be related to the integrity of both the hippocampus and cortex [32]. The onset of $\mathrm{CCH}$ is in the associative cortical areas; then, it spreads throughout the brain via the neuronal network, affecting cognitive function [33]. Our previous studies also showed that $\mathrm{CCH}$ resulted in hypoperfusion of cortical cerebral blood flow in rats, as well as white matter fiber injury and neuron death in the cortex $[7,9]$. Considering cerebral white matter is comprised of nerve fibers that interconnect neurons in the cortex or the deep structures [34], pathological changes in the cerebral cortex caused by $\mathrm{CCH}$ could also be associated with cognitive impairment. Therefore, we focused on the $\mathrm{CCH}$ effects on cortex in this study. We found APN-P not only regulated microglial polarization changes in the cortex of $\mathrm{CCH}$ rats but also showed a protective effect on cortical and hippocampal neurons in vivo. In vitro results also indicated a neuroprotective effect in the two neuronal cell lines when co-cultured with activated BV2 microglia cells. Together, these results indicated that APN-P treatment could reduce cortex injury through the mediation of pro- and antiinflammatory responses that contribute to $\mathrm{CCH}$ tissue damage, further suggesting a therapeutic potential for ANP-P treatment strategies for cortex injuries.

$\mathrm{CCH}$ causes a cascade of pathological processes during which diverse signaling pathways are activated [30]. Our in vivo study found that $\mathrm{CCH}$ could activate the NF- $\mathrm{kB}$ signaling pathways, which are closely related to neuroinflammation [35] and can induce the production of proinflammatory molecules that promote apoptosis in neural cells and cause secondary neurotoxicity

537 [36]. A previous study indicated that APN inhibits ROS-induced cardiac remodeling in rat ventricular myocytes by inhibiting NF- $\mathrm{kB}$ activation and that APN mediates the suppression of NF$\kappa \mathrm{B}$ activation and pro-inflammatory cytokine expression, leading to a suppression of $\mathrm{M} 1$ macrophage proliferation and function [15]. Consistent with these previous findings, we observed 
that APN-P could efficiently inhibit NF- $\mathrm{kB}$ activation in the cortex of $\mathrm{CCH}$ rats, and our in vitro results from LPS-activated BV2 microglial cells showed that an NF-kB inhibitor and and APN-P

543 treatment could mediate the suppression of M1 polarization and pro-inflammatory factor expression.

544 Consistent with the effect of the NF-kB inhibitor, APN-P mediated the promotion of M2 polarization 545 and anti-inflammatory factor expression in LPS-induced BV2 cells.

This study has several limitations. First, APN-P-mediated protection after $\mathrm{CCH}$ was studied

547 using a single dose concentration; future studies should assess concentration-dependent effects of

APN-P. Second, we focused on changes in microglial cells after CCH and APN-P treatment, but the potential effects on microglia-neuron crosstalk deserve further exploration. Third, exploration of the effects of APN-P on $\mathrm{CCH}$ in aging, diabetes, or obesity is warranted in follow-up studies due to the vital role of APN in metabolic regulation. Finally, none of the experimental $\mathrm{CCH}$ models currently in use can completely mimic the clinical $\mathrm{CCH}$ process, and before clinical application, the translational challenges of this novel treatment must be fully considered.

\section{Conclusions}

Collectively, APN downregulation is involved in $\mathrm{CCH}$-induced polarization of cortex microglia toward the pro-inflammatory M1 phenotype. APN-P showed neuroprotective effects against neuron damage after $\mathrm{CCH}$, which alleviated microglia-derived inflammation and regulated the transformation of microglial cells to the anti-inflammatory M2 phenotype. These effects were mediated by the suppression of NF- $\mathrm{KB}$ signaling. This study provides a novel and potentially therapeutic strategy for future clinical application of APN-P in the treatment of $\mathrm{CCH}$-induced cognitive impairment in human patients. 


\section{Abbreviations}

$565 \mathrm{CCH}$, Chronic cerebral hypoperfusion; APN, Adiponectin; APN-P, Recombinant adiponectin

566 peptide; BCCAO, Bilateral common carotid artery occlusion; CBF, Cerebral blood flow; LPS,

567 Lipopolysaccharide; qRT-PCR, Quantitative reverse transcription polymerase chain reaction; BAY,

568 BAY 11-7082; EL, Escape latency; RIPA, Radio-Immunoprecipitation Assay; SDS-PAGE, sodium

569 dodecyl sulfatepolyacrylamide gel; PVDF, polyvinylidene difluoride; TBST, Tris-buffered saline

570 and Tween-20; Arg-1, Arginase-1; IL-6, Interleukin-6; IL-18, Interleukin-18; IL-1 $\beta$, Interleukin-1 $\beta$;

571 TNF- $\alpha$, Tumor necrosis factor- $\alpha$; IL-10, Interleukin-10; TGF- $\beta$, Transforming growth factor- $\beta$; ROS,

572 Reactive oxygen species; ROI, Region of interest for quantitative analysis.

573

\section{Ethics approval and consent to participate}

575 All protocols were approved by the Animal Care and Use Committee of Xi'an Jiaotong University

576 and conformed to the Guide for the Care and Use of Laboratory Animals by the National Institutes 577 of Health, USA.

\section{Consent for publication}

$580 \quad$ Not applicable.

\section{Availability of data and materials}

583 The datasets generated and/or analyzed in the current study are available from the corresponding author on reasonable request. 


\section{Competing interests}

587 The authors declare that they have no competing interests.

\section{Funding}

This work was supported by the National Natural Science Foundation of China (No. 81971120, No.

81971116), the National Natural Science Foundation of Guangdong province (No.

\section{Authors' contributions}

Wenxian Li, Di Wei and Zheng Zhu wrote the paper and performed the most of experiments. Shuqin

Zhan, Ru Zhang and Huqing Wang collected and analyzed the data. Guilian Zhang and Li'an Huang

designed the research and revised the manuscript.

\section{Acknowledgments}

We thank the support from the Department of Neurology, The Second Affiliated Hospital, Xi'an editing and polishing the manuscript.

603

\section{Author details}

${ }^{1}$ Department of Neurology, The Second Affiliated Hospital, Xi'an jiaotong University, Xi'an, 

China.

${ }^{3}$ Department of Internal Medicine, Division of Hematology/Oncology, University of California China.

\section{Reference}

1. Liu Q, Radwanski R, Babadjouni R, Patel A, Hodis DM, Baumbacher P, Zhao Z, Zlokovic B and Mack WJ. Experimental chronic cerebral hypoperfusion results in decreased pericyte coverage and increased blood-brain barrier permeability in the corpus callosum. Journal of cerebral blood flow and metabolism : official journal of the International Society of Cerebral Blood Flow and Metabolism. 2019; 39(2):240-250.

620 2. Fang C, Li Q, Min G, Liu M, Cui J, Sun J and Li L. MicroRNA-181C Ameliorates Cognitive

621 Impairment Induced by Chronic Cerebral Hypoperfusion in Rats. Molecular neurobiology. 2017; 622 54(10):8370-8385.

623 3. Zou W, Song Y, Li Y, Du Y, Zhang X and Fu J. The Role of Autophagy in the Correlation 624 Between Neuron Damage and Cognitive Impairment in Rat Chronic Cerebral Hypoperfusion. 625 Molecular neurobiology. 2018; 55(1):776-791.

626 4. Du SQ, Wang XR, Xiao LY, Tu JF, Zhu W, He T and Liu CZ. Molecular Mechanisms of Vascular 627 Dementia: What Can Be Learned from Animal Models of Chronic Cerebral Hypoperfusion? 628 Molecular neurobiology. 2017; 54(5):3670-3682.

629 5. Su SH, Wu YF, Lin Q, Wang DP and Hai J. URB597 protects against NLRP3 inflammasome 630 activation by inhibiting autophagy dysfunction in a rat model of chronic cerebral hypoperfusion. 631 Journal of neuroinflammation. 2019; 16(1):260.

632 6. Ren C, Li N, Li S, Han R, Huang Q, Hu J, Jin K and Ji X. Limb Ischemic Conditioning Improved 633 Cognitive Deficits via eNOS-Dependent Augmentation of Angiogenesis after Chronic Cerebral 634 Hypoperfusion in Rats. Aging and disease. 2018; 9(5):869-879.

635 7. Li W, Wei D, Lin J, Liang J, Xie X, Song K and Huang L. DI-3-n-Butylphthalide Reduces 636 Cognitive Impairment Induced by Chronic Cerebral Hypoperfusion Through GDNF/GFRalpha1/Ret 637 Signaling Preventing Hippocampal Neuron Apoptosis. Frontiers in cellular neuroscience. 2019; $638 \quad 13: 351$.

639 8. Song D, Zhang X, Chen J, Liu X, Xue J, Zhang L and Lan X. Wht canonical pathway activator 640 TWS119 drives microglial anti-inflammatory activation and facilitates neurological recovery 641 following experimental stroke. Journal of neuroinflammation. 2019; 16(1):256.

642 9. Li W, Wei D, Liang J, Xie X, Song K and Huang L. Comprehensive Evaluation of White Matter 
Damage and Neuron Death and Whole-Transcriptome Analysis of Rats With Chronic Cerebral Hypoperfusion. Frontiers in cellular neuroscience. 2019; 13:310.

10. Chen X, Jiang XM, Zhao LJ, Sun LL, Yan ML, Tian Y, Zhang S, Duan MJ, Zhao HM, Li WR, Hao YY, Wang LB, Xiong QJ and Ai J. MicroRNA-195 prevents dendritic degeneration and neuron death in rats following chronic brain hypoperfusion. Cell death \& disease. 2017; 8(6):e2850.

11. Nishio K, Ihara M, Yamasaki N, Kalaria RN, Maki T, Fujita $Y$, Ito H, Oishi N, Fukuyama $H$, Miyakawa T, Takahashi R and Tomimoto $\mathrm{H}$. A mouse model characterizing features of vascular dementia with hippocampal atrophy. Stroke. 2010; 41(6):1278-1284.

12. Mao M, Xu Y, Zhang XY, Yang L, An XB, Qu Y, Chai YN, Wang YR, Li TT and Ai J. MicroRNA195 prevents hippocampal microglial/macrophage polarization towards the M1 phenotype induced by chronic brain hypoperfusion through regulating CX3CL1/CX3CR1 signaling. Journal of neuroinflammation. 2020; 17(1):244.

13. Chi GC, Fitzpatrick AL, Sharma M, Jenny NS, Lopez OL and DeKosky ST. Inflammatory Biomarkers Predict Domain-Specific Cognitive Decline in Older Adults. The journals of gerontology Series A, Biological sciences and medical sciences. 2017; 72(6):796-803.

14. Liu R, Liao XY, Pan MX, Tang JC, Chen SF, Zhang Y, Lu PX, Lu LJ, Zou YY, Qin XP, Bu LH and Wan Q. Glycine Exhibits Neuroprotective Effects in Ischemic Stroke in Rats through the Inhibition of M1 Microglial Polarization via the NF-kappaB p65/Hif-1alpha Signaling Pathway. Journal of immunology (Baltimore, Md : 1950). 2019; 202(6):1704-1714.

15. Fang $\mathrm{H}$ and Judd RL. Adiponectin Regulation and Function. Comprehensive Physiology. 2018; 8(3):1031-1063.

16. Wu X, Luo J, Liu H, Cui W, Guo W, Zhao L, Guo H, Bai H, Guo K, Feng D and Qu Y. Recombinant adiponectin peptide promotes neuronal survival after intracerebral haemorrhage by suppressing mitochondrial and ATF4-CHOP apoptosis pathways in diabetic mice via Smad3 signalling inhibition. Cell proliferation. 2020; 53(2):e12759.

17. Li X, Guo H, Zhao L, Wang B, Liu H, Yue L, Bai H, Jiang H, Gao L, Feng D and Qu Y. Adiponectin attenuates NADPH oxidase-mediated oxidative stress and neuronal damage induced by cerebral ischemia-reperfusion injury. Biochimica et biophysica acta Molecular basis of disease. 2017; 1863(12):3265-3276.

18. Wang B, Guo H, Li X, Yue L, Liu H, Zhao L, Bai H, Liu X, Wu X and Qu Y. Adiponectin Attenuates Oxygen-Glucose Deprivation-Induced Mitochondrial Oxidative Injury and Apoptosis in Hippocampal HT22 Cells via the JAK2/STAT3 Pathway. Cell transplantation. 2018; 27(12):17311743

19. Huang TF, Tang ZP, Wang S, Hu MW, Zhan L, Yi Y, He YL and Cai ZY. Decrease in Serum Levels of Adiponectin and Increase in 8-OHdG: a Culprit for Cognitive Impairment in the Elderly Patients with Type 2 Diabetes. Current molecular medicine. 2019; 20(1):44-50.

20. Efstathiou SP, Tsioulos DI, Tsiakou AG, Gratsias YE, Pefanis AV and Mountokalakis TD. Plasma adiponectin levels and five-year survival after first-ever ischemic stroke. Stroke. 2005; 36(9):19151919.

21. Wu X, Luo J, Liu H, Cui W, Guo K, Zhao L, Bai H, Guo W, Guo H, Feng D and Qu Y. Recombinant Adiponectin Peptide Ameliorates Brain Injury Following Intracerebral Hemorrhage by Suppressing Astrocyte-Derived Inflammation via the Inhibition of Drp1-Mediated Mitochondrial Fission. Translational stroke research. 2020.

22. Sun H, Chen GY and Yao SQ. Recent advances in microarray technologies for proteomics. 
Chemistry \& biology. 2013; 20(5):685-699.

23. Wu X, Luo J, Liu H, Cui W, Guo K, Zhao L, Bai H, Guo W, Guo H, Feng D and Qu Y. Recombinant Adiponectin Peptide Ameliorates Brain Injury Following Intracerebral Hemorrhage by Suppressing Astrocyte-Derived Inflammation via the Inhibition of Drp1-Mediated Mitochondrial Fission. Translational stroke research. 2020; 11(5):924-939.

24. Li W, Wei D, Xie X, Liang J, Song K and Huang L. DI-3-n-Butylphthalide regulates the Ang1/Ang-2/Tie-2 signaling axis to promote neovascularization in chronic cerebral hypoperfusion. Biomedicine \& pharmacotherapy = Biomedecine \& pharmacotherapie. 2019; 113:108757. 25. Zhang Z, Qin P, Deng Y, Ma Z, Guo H, Hou Y, Wang S, Zou W, Sun Y, Ma Y and Hou W. The novel estrogenic receptor GPR30 alleviates ischemic injury by inhibiting TLR4 -mediated microglial inflammation. Journal of neuroinflammation. 2018; 15(1):206.

26. Nam HY, Nam JH, Yoon G, Lee JY, Nam Y, Kang HJ, Cho HJ, Kim J and Hoe HS. Ibrutinib suppresses LPS-induced neuroinflammatory responses in BV2 microglial cells and wild-type mice. Journal of neuroinflammation. 2018; 15(1):271.

27. Yue L, Zhao L, Liu H, Li X, Wang B, Guo H, Gao L, Feng D and Qu Y. Adiponectin Protects against Glutamate-Induced Excitotoxicity via Activating SIRT1-Dependent PGC-1 $\alpha$ Expression in HT22 Hippocampal Neurons. Oxidative medicine and cellular longevity. 2016; 2016:2957354.

28. Letra L, Rodrigues T, Matafome P, Santana I and Seiça R. Adiponectin and sporadic Alzheimer's disease: Clinical and molecular links. Frontiers in neuroendocrinology. 2019; 52:1-11. 29. Zhang LY, Pan J, Mamtilahun M, Zhu Y, Wang L, Venkatesh A, Shi R, Tu X, Jin K, Wang Y, Zhang $Z$ and Yang GY. Microglia exacerbate white matter injury via complement C3/C3aR pathway after hypoperfusion. Theranostics. 2020; 10(1):74-90.

30. Zhang J, Liu Y, Zheng Y, Luo Y, Du Y, Zhao Y, Guan J, Zhang X and Fu J. TREM-2-p38 MAPK signaling regulates neuroinflammation during chronic cerebral hypoperfusion combined with diabetes mellitus. Journal of neuroinflammation. 2020; 17(1):2.

31. Wang LY, Tao Z, Zhao HP, Wang RL, Li LZ, Luo YM and Chen ZG. Huoluo Yinao decoction mitigates cognitive impairments after chronic cerebral hypoperfusion in rats. Journal of ethnopharmacology. 2019; 238:111846.

32. Block F and Schwarz M. Correlation between hippocampal neuronal damage and spatial learning deficit due to global ischemia. Pharmacology, biochemistry, and behavior. 1997; 56(4):755-761.

33. Völgyi K, Gulyássy P, Todorov MI, Puska G, Badics K, Hlatky D, Kékesi KA, Nyitrai G, Czurkó A, Drahos $L$ and Dobolyi A. Chronic Cerebral Hypoperfusion Induced Synaptic Proteome Changes in the rat Cerebral Cortex. Molecular neurobiology. 2018; 55(5):4253-4266.

34. Tomimoto $H$. White matter integrity and cognitive dysfunction: Radiological and neuropsychological correlations. Geriatrics \& gerontology international. 2015; 15 Suppl 1:3-9.

35. Shih RH, Wang CY and Yang CM. NF-kappaB Signaling Pathways in Neurological Inflammation: A Mini Review. Frontiers in molecular neuroscience. 2015; 8:77.

36. Li B, Dasgupta C, Huang L, Meng $X$ and Zhang L. MiRNA-210 induces microglial activation and regulates microglia-mediated neuroinflammation in neonatal hypoxic-ischemic encephalopathy. Cellular \& molecular immunology. 2020; 17(9):976-991. 


\section{Figure Legends}

Fig. 1 Microglial activation and decreased expression of APN in the cortex of $\mathrm{CCH}$ rats.

733 a. A flowchart of the animal experiments.

b. Representative images of Iba- $1+$ and $\mathrm{NeuN}+$ cells in the cortexes of sham and $\mathrm{CCH}$ rats at the $2^{\text {nd }}, 4^{\text {th }}, 8^{\text {th }}$, and $12^{\text {th }}$ week after BCCAO surgery. Magnification $\times 20$, scale bar $=100 \mu \mathrm{m}$.

c. Quantification of the Iba-1+ cells in the cortex region of rats in different groups.

d. There was a negative correlation between the $\mathrm{Iba}-1+$ and $\mathrm{NeuN}+$ cell numbers.

Values are mean $\pm \mathrm{SD}, \mathrm{n}=3$ slices from 4 animals per group, ${ }^{*} \mathrm{P}<0.05,{ }^{*} \mathrm{P}<0.01$ vs sham group, Student's $\mathrm{t}$ test and Pearson correlation analysis. ROI, $200 \mu \mathrm{m}^{2}$.

e. A heat map representation of the protein level analysis of antibody arrays that show that APN was the most statistically significant among 10 proteins in the cortex of $\mathrm{CCH} 12 \mathrm{w}$ rats compared to the sham (fold change $=-4.23, \mathrm{P}<0.05 ; \mathrm{n}=6$ animals per group). rats at the $12^{\text {th }}$ week after BCCAO surgery. Magnification $\times 60$, scale bar $=30 \mu \mathrm{m}$. Values are mean $\pm \mathrm{SD}, \mathrm{n}=3$ slices from 3 animals per group, ${ }^{* *} \mathrm{P}<0.01$ vs sham group, Student's $\mathrm{t}$ test. ROI, $100 \mu \mathrm{m}^{2}$.

751 a. The amino acid sequence of APN-P [23]. 
vivo.

754

755

d. Representative images of CD16 expression in Iba-1+ cells in the cortex of sham, $\mathrm{CCH}$, and $\mathrm{CCH}$ rats with APN-P treatment groups. Magnification $\times 60$, scale bar $=30 \mu \mathrm{m}$.

e. Representative images of CD206 expression in Iba-1+ cells in cortex of sham, $\mathrm{CCH}$ and, $\mathrm{CCH}$ with APN-P treatment groups. Magnification $\times 60$, scale bar $=30 \mu \mathrm{m}$.

f. Quantification of the Iba-1+ cell number in the cortex of different treatment groups.

g. Quantification of CD16 in Iba-1+ cells (\%) in the cortex of different treatment groups.

h. Quantification of CD206 in Iba-1+ cells (\%) in the cortex of different groups.

i. Quantification of the CD16/CD206 ratio in the cortex of different treatment groups.

j. Quantification of the CD206/CD16 ratio in the cortex of different treatment groups.

Values are mean $\pm \mathrm{SD}, \mathrm{n}=3$ slices from 3 animals per group, ${ }^{* *} \mathrm{P}<0.01 \mathrm{CCH}$ vs sham groups, \#\#P $<0.01 \mathrm{CCH}+\mathrm{APN}-\mathrm{P}$ vs CCH groups, One way ANOVA test, Tukey tests. ROI, $100 \mu \mathrm{m}^{2}$.

Fig. $3 \mathrm{CCH}$ induces inflammatory responses, while APN-P treatment induces antiinflammatory responses in the rat cortex

The mRNA expression of (a) $i N O S$, (b) $I L-6$, (c) $I L-18$, (d) $I L-1 \beta$, (e) $T N F-\alpha$, (f) $A r g-1$, (g) $I L-10$, and (h) $T G F-\beta$ in the cortex of rats in different groups. Values are mean $\pm \mathrm{SD}, \mathrm{n}=6$ animals per group, ${ }^{* *} \mathrm{P}<0.01 \mathrm{CCH}$ vs sham groups, \#\#P $<0.01 \mathrm{CCH}+\mathrm{APN}-\mathrm{P}$ vs $\mathrm{CCH}$ groups, One way ANOVA test, Tukey tests.

\section{Fig. 4 APN-P promotes the microglia M2 phenotype in LPS-induced BV2 cells}

Representative immunofluorescent images of (a) CD16 and (b) CD206 expression in Iba-1+ cells 

$30 \mu \mathrm{m}$.

Quantification of (c) CD16 in Iba-1+ cells (\%), (d) CD206 in Iba-1+ cells (\%), (e) CD16/CD206 ratio, and (f) CD206/CD16 ratio in BV2 cells of different groups.

Values are mean $\pm \mathrm{SD}, \mathrm{n}=3$ slices from 3 animals per group, ${ }^{* *} \mathrm{P}<0.01$ LPS vs control group, \#\#P $<0.01$ vs LPS group, One way ANOVA test, Tukey tests. ROI, $100 \mu \mathrm{m}^{2}$.

Fig. 5 APN-P promotes the microglial M2 phenotype and anti-inflammatory responses via NF-

\section{КB pathway inhibition}

a. Western blotting analysis of in vivo NF- $\mathrm{BB}$ and $\mathrm{p}-\mathrm{NF}-\mathrm{\kappa B}$ protein expression.

b. Quantification of the in vivo $\mathrm{p}-\mathrm{NF}-\mathrm{kB} / \mathrm{NF}-\mathrm{kB}$ ratio.

Values are mean $\pm \mathrm{SD}, \mathrm{n}=3$ samples per group, $* * \mathrm{P}<0.01 \mathrm{CCH}$ vs sham group, \#\#P $<0.01$

c. Western blotting analysis of the protein expression of NF-kB, p-NF-kB, iNOS and Arg-1 in vivo. in control, LPS treatment, LPS + BAY and LPS + APN-P treated groups.

Values are mean $\pm \mathrm{SD}, \mathrm{n}=3$ samples per group, ${ }^{*} \mathrm{P}<0.05,{ }^{*} \mathrm{P}<0.01$ LPS vs control group, $\# \mathrm{P}<$ 0.05, \#\#P $<0.01$ vs LPS group, One way ANOVA test, Tukey tests. and (m) $T G F-\beta$ in BV2 cells in different groups.

Values are mean $\pm \mathrm{SD}, \mathrm{n}=6$ samples per group, $* * \mathrm{P}<0.01$ LPS vs control group, \#\#P $<0.01$ vs 
Fig. 6 Effects of APN-P on neuron protection

799 a. Sections of the cortex and the hippocampal CA1 region were obtained and treated with Nissl

800 staining. Magnification $\times 40$, scale bar $=50 \mu \mathrm{m}$.

801 b. Quantitative analysis of neuronal damage of the cortex region.

802

c. Quantitative analysis of neuronal damage of the hippocampal CA1 region.

Values are mean $\pm \mathrm{SD}, \mathrm{n}=3$ samples per group, $* * \mathrm{P}<0.01 \mathrm{CCH}$ vs sham group, \#\#P $<0.01$ $\mathrm{CCH}+\mathrm{APN}-\mathrm{P}$ vs $\mathrm{CCH}$ group, One way ANOVA test, Tukey tests. ROI, $200 \mu \mathrm{m}^{2}$.

d. Flowchart of in vitro experiments (a microglia-neuron co-culture system). using a CCK-8 test.

Values are mean $\pm \mathrm{SD}, \mathrm{n}=5$ samples per group, ${ }^{* *} \mathrm{P}<0.01$ LPS vs control group, \#\#P $<0.01$ vs LPS group, One way ANOVA test, Tukey tests. cells. Magnification $\times 40$, scale bar $=100 \mu \mathrm{m}$.

g. The quantification of the CMFDA fluorescence intensity in different groups.

Values are mean $\pm \mathrm{SD}, \mathrm{n}=3$ samples per group, $* * \mathrm{P}<0.01$ LPS vs control group, \#\#P $<0.01$ vs LPS group, One way ANOVA test, Tukey tests. 

APN-P vs CCH 8w group; **”P $<0.01 \mathrm{CCH} 12 \mathrm{w}$ vs sham group, \#\#”P $<0.01 \mathrm{CCH} 12 \mathrm{w}+\mathrm{APN}-$ $\mathrm{P}$ vs CCH 12w group, Two-way ANOVA, Bonferroni post hoc test. were significantly different from each other on day 6 . + APN-P vs CCH group, Two-way ANOVA, Bonferroni post hoc test. Morris water maze.

APN-P inhibited the NF- $\mathrm{KB}$ pathway and regulated microglial polarization from an M1 toward an CCH-induced cognitive impairment.

\section{Additional files}

Additional file 1

Table S1. Animal groups and number of rats used in the research. The number of rats in each group for each test were shown in the Table.

\section{Additional file 2}

Figure S1. Full gels of APN, iNOS, Arg-1, NF- $\mathrm{BB}, \mathrm{p}-\mathrm{NF}-\mathrm{\kappa B}$ and $\beta$-actin in vivo and in vitro. 
a

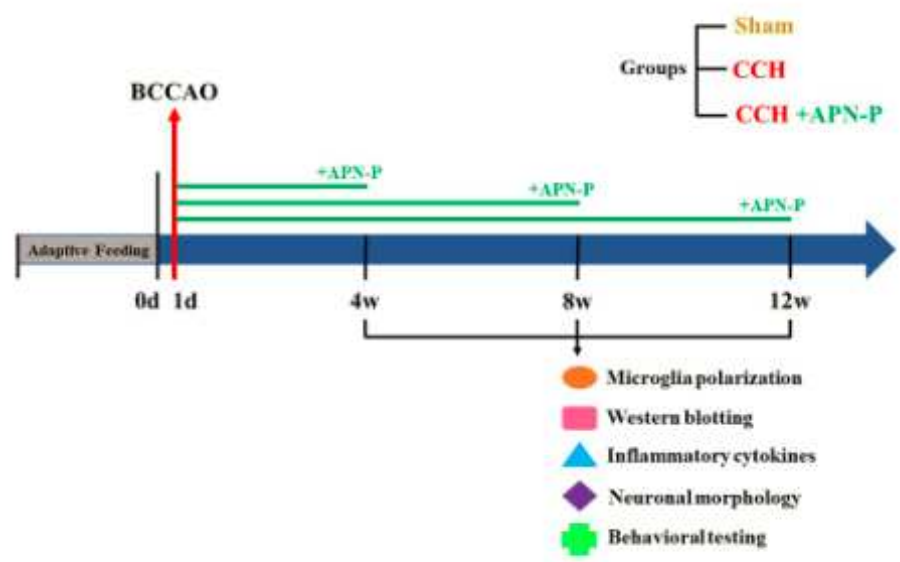

b

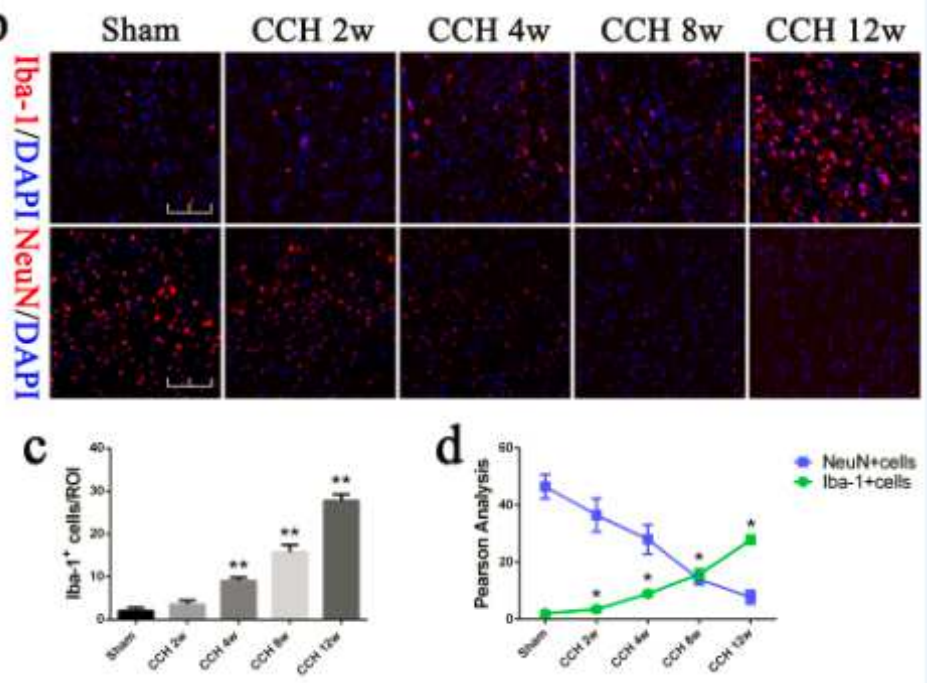

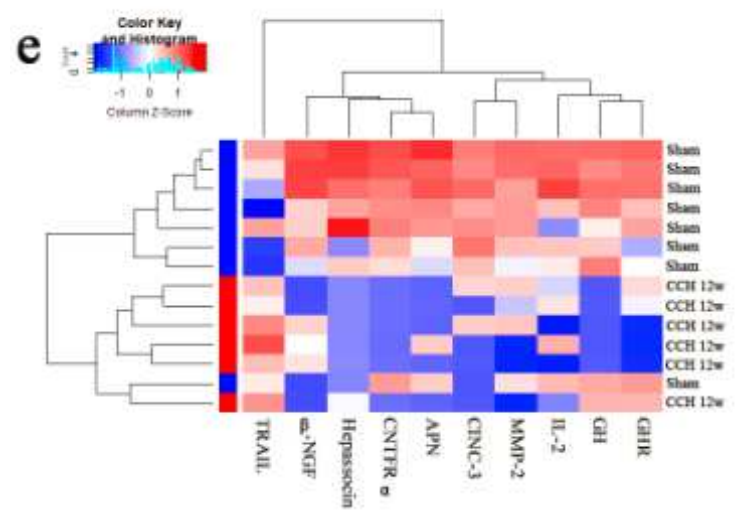
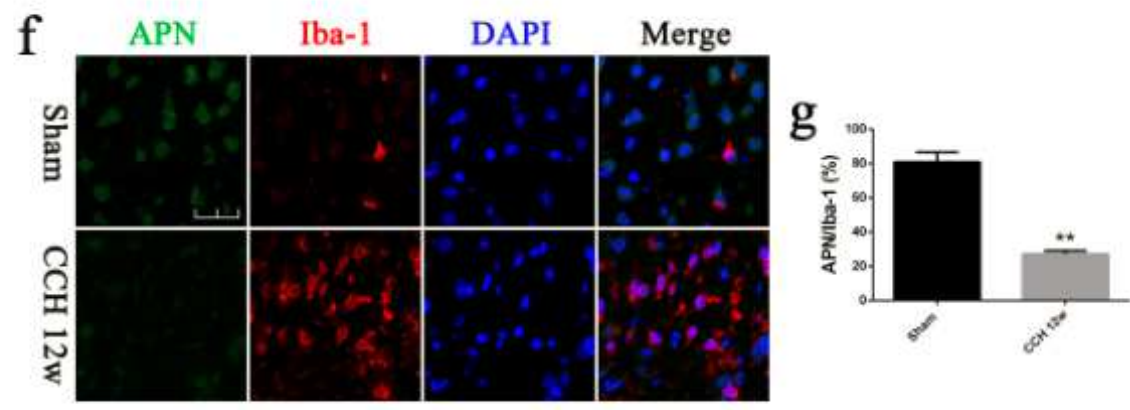

\section{Figure 1}

Microglial activation and decreased expression of APN in the cortex of $\mathrm{CCH}$ rats. a. A flowchart of the animal experiments. b. Representative images of Iba- $1+$ and $\mathrm{NeuN}+$ cells in the cortexes of sham and $\mathrm{CCH}$ rats at the 2nd, 4th, 8th, and 12th week after BCCAO surgery. Magnification $\times 20$, scale bar $=100 \mu \mathrm{m}$.

c. Quantification of the lba-1+ cells in the cortex region of rats in different groups. $d$. There was a negative correlation between the Iba- $1+$ and $\mathrm{NeuN}+$ cell numbers. Values are mean $\pm \mathrm{SD}, \mathrm{n}=3$ slices from 4 animals per group, ${ }^{\star} \mathrm{P}<0.05,{ }^{*} \mathrm{P}<0.01$ vs sham group, Student's $\mathrm{t}$ test and Pearson correlation analysis. $\mathrm{ROI}, 200 \mu \mathrm{m} 2$. e. A heat map representation of the protein level analysis of antibody arrays that show that APN was the most statistically significant among 10 proteins in the cortex of $\mathrm{CCH} 12 \mathrm{w}$ rats compared to the sham (fold change $=-4.23, \mathrm{P}<0.05 ; \mathrm{n}=6$ animals per group). $\mathrm{f}$. Representative images of APN expression in Iba- $1+$ cells in the cortex region of sham and $\mathrm{CCH}$ rats at the 12th week after BCCAO surgery. Magnification $\times 60$, scale bar $=30 \mu \mathrm{m}$. g. Quantification of the ratio of APN in Iba- $1+$ cells in cortex region. Values are mean $\pm S D, n=3$ slices from 3 animals per group, $* * P<0.01$ vs sham group,

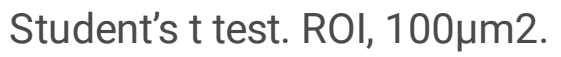



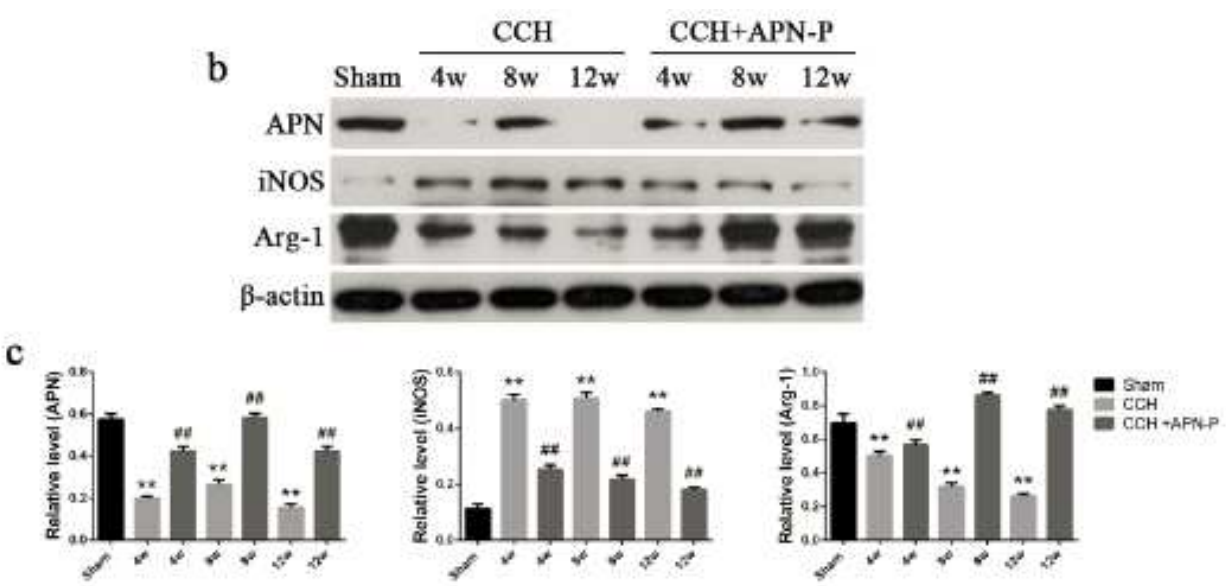

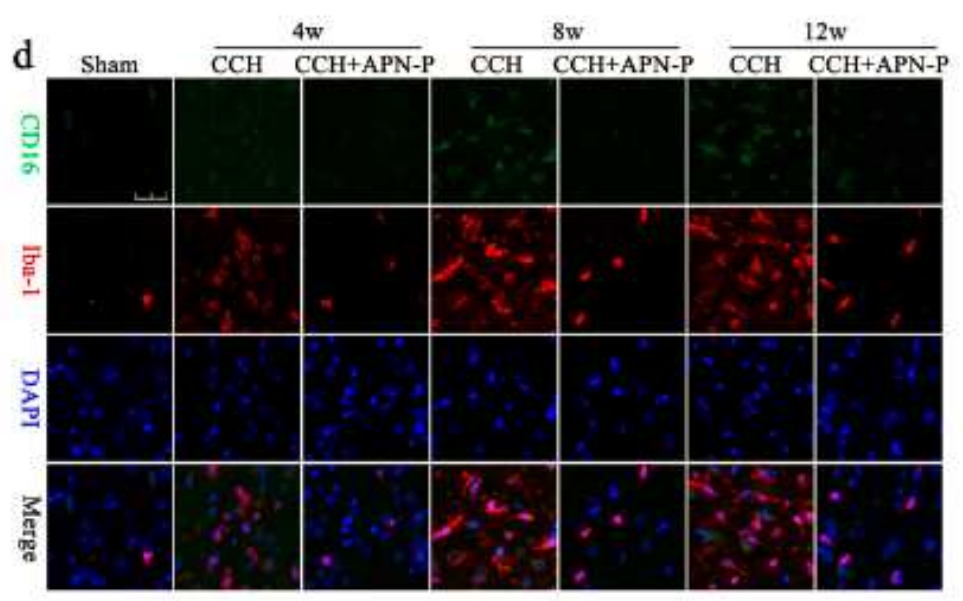

f

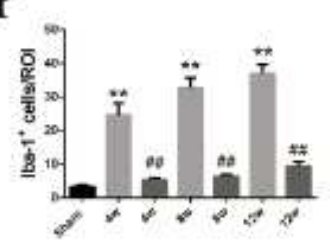

g

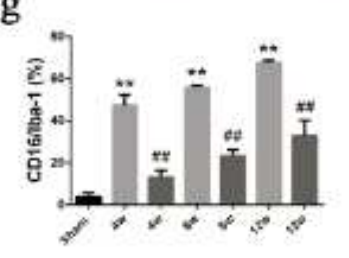

$\mathrm{h}$

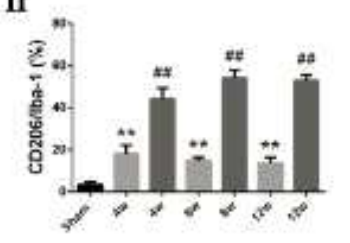

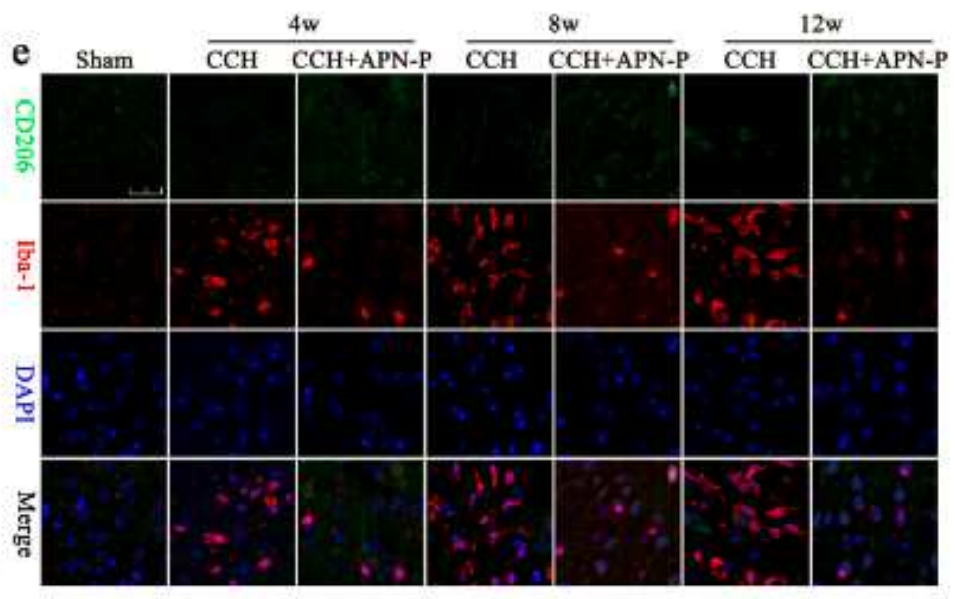

i

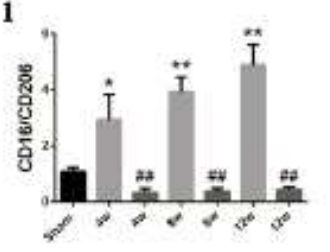

j

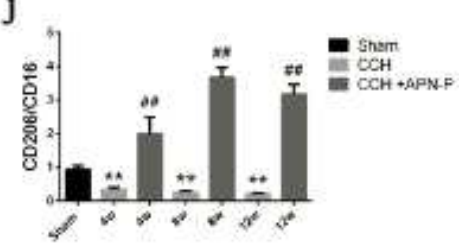

Figure 2

$\mathrm{CCH}$ polarizes microglia toward M1 phenotypes, while APN-P promotes M2 phenotypes in the rat cortex a. The amino acid sequence of APN-P [23]. b, c. Western blotting analysis of the relative protein levels of APN, iNOS, and Arg-1 expressed in vivo. d. Representative images of CD16 expression in Iba- $1+$ cells in the cortex of sham, $\mathrm{CCH}$, and $\mathrm{CCH}$ rats with APN-P treatment groups. Magnification $\times 60$, scale bar $=30$ $\mu \mathrm{m}$. e. Representative images of $\mathrm{CD} 206$ expression in lba-1+ cells in cortex of sham, $\mathrm{CCH}$ and, $\mathrm{CCH}$ with APN-P treatment groups. Magnification $\times 60$, scale bar $=30 \mu \mathrm{m}$. $\mathrm{f}$. Quantification of the Iba- $1+$ cell number in the cortex of different treatment groups. g. Quantification of CD16 in Iba-1+ cells (\%) in the cortex of different treatment groups. h. Quantification of CD206 in Iba-1+ cells (\%) in the cortex of different groups. i. Quantification of the CD16/CD206 ratio in the cortex of different treatment groups. j. Quantification of the CD206/CD16 ratio in the cortex of different treatment groups. Values are mean $\pm S D, n=3$ slices from 3 animals per group, ${ }^{\star *} \mathrm{P}<0.01 \mathrm{CCH}$ vs sham groups, \#\#P<0.01 CCH+APN-P vs CCH groups, One way

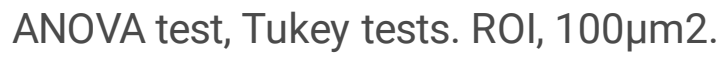



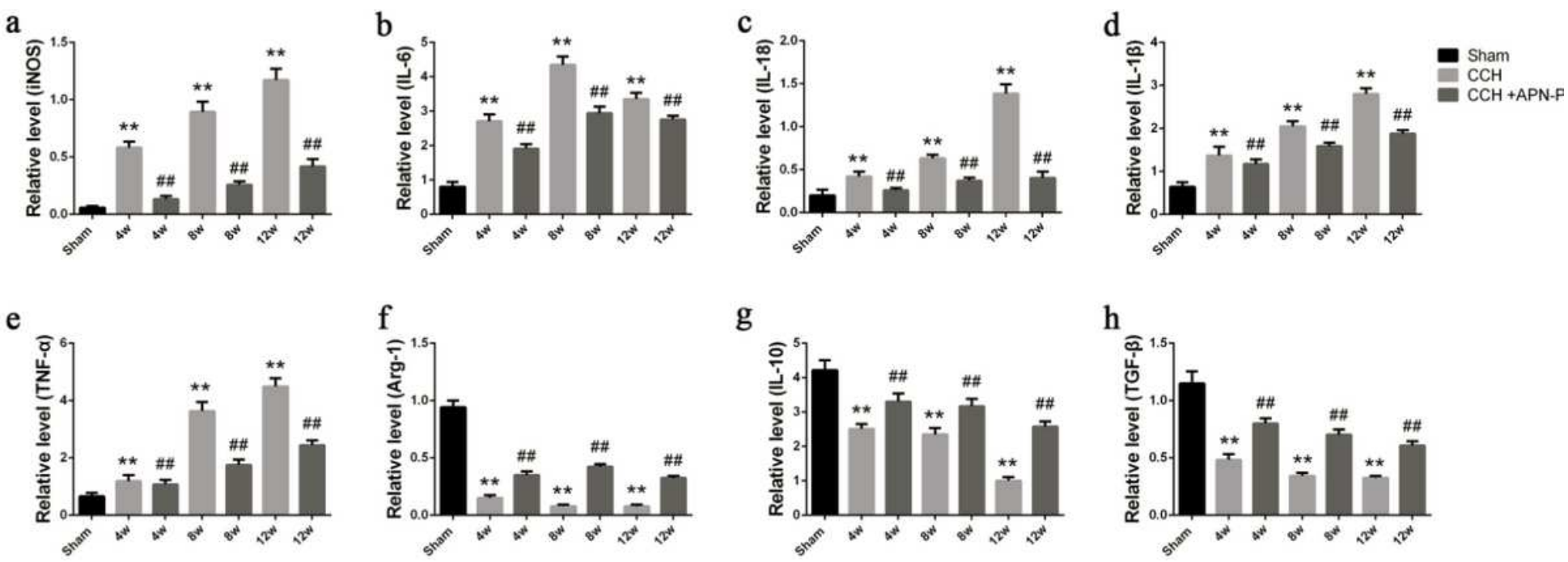

Figure 3

$\mathrm{CCH}$ induces inflammatory responses, while APN-P treatment induces anti-inflammatory responses in the rat cortex the mRNA expression of (a) iNOS, (b) IL-6, (c) IL-18, (d) IL-1ß, (e) TNF-a, (f) Arg-1, (g) IL-10, and (h) TGF- $\beta$ in the cortex of rats in different groups. Values are mean $\pm S D, n=6$ animals per group, $* * P<$ $0.01 \mathrm{CCH}$ vs sham groups, \#\#P<0.01 CCH+APN-P vs CCH groups, One way ANOVA test, Tukey tests.
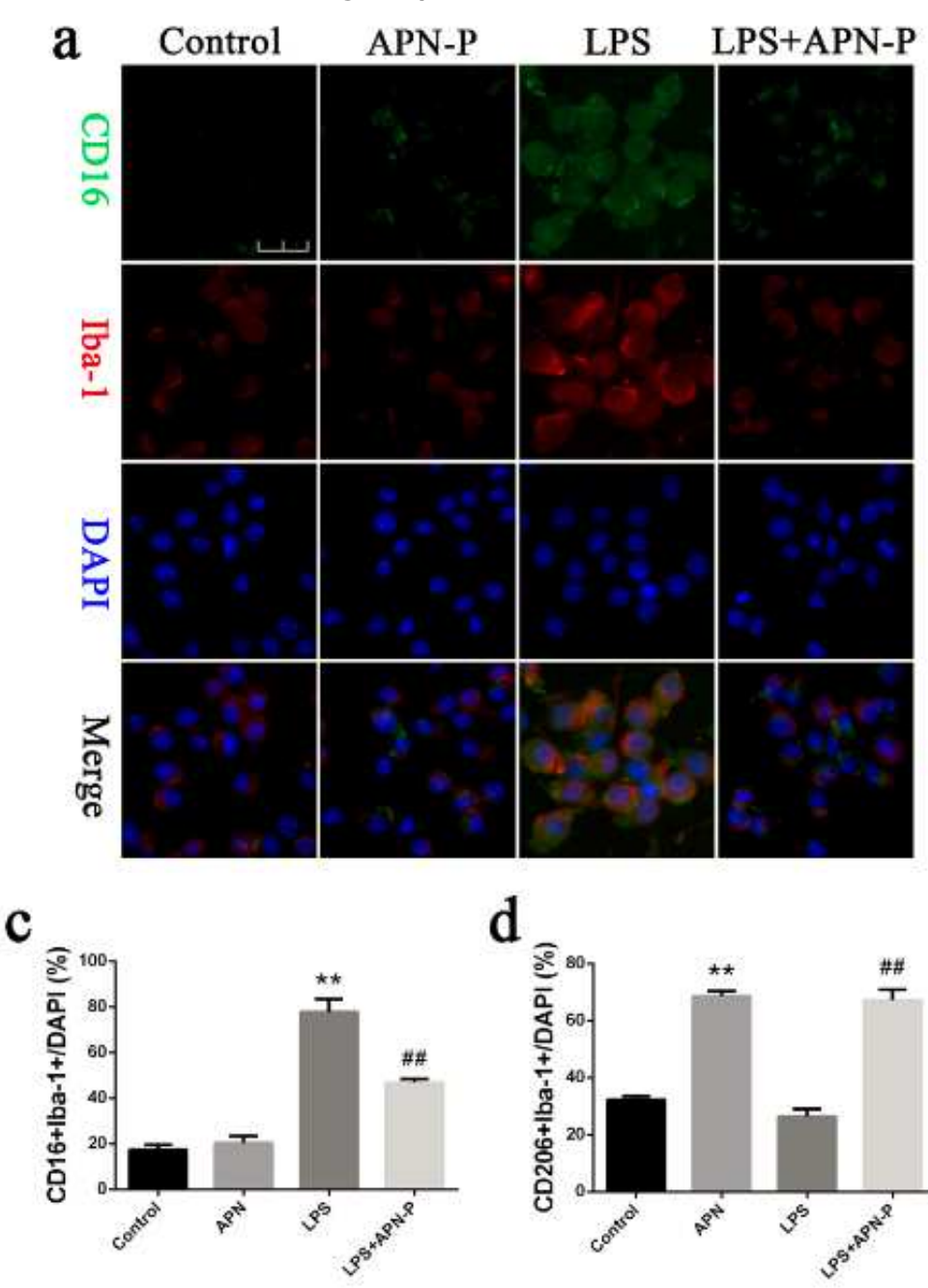

d

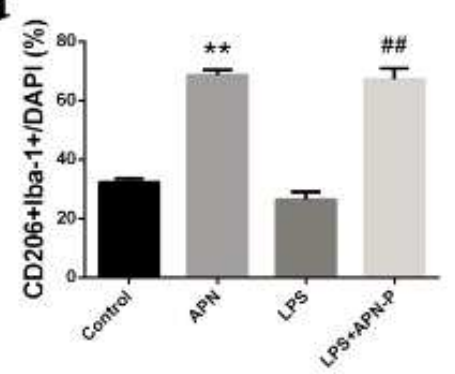

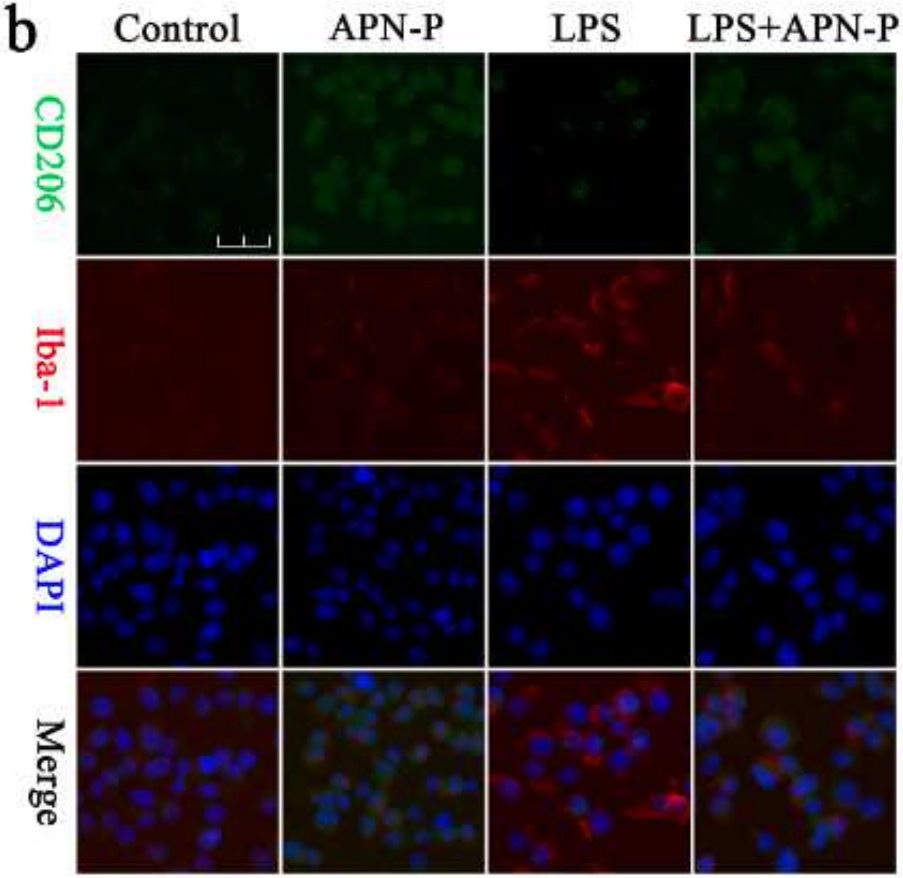

e

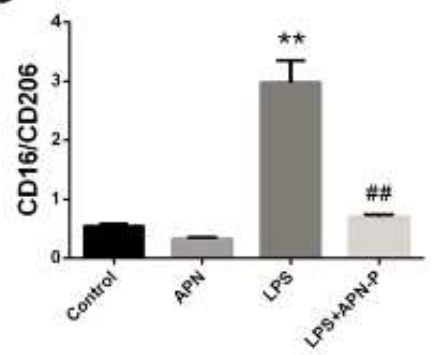

f

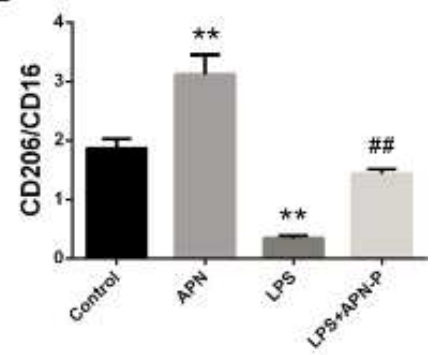




\section{Figure 4}

APN-P promotes the microglia M2 phenotype in LPS-induced BV2 cells Representative immunofluorescent images of (a) CD16 and (b) CD206 expression in Iba-1+ cells in BV2 cells from control, LPS, and LPS+APN-P treatment groups. Magnification $\times 60$, scale bar $=30 \mu \mathrm{m}$. Quantification of (c) CD16 in Iba-1+ cells (\%), (d) CD206 in Iba-1+ cells (\%), (e) CD16/CD206 ratio, and (f) CD206/CD16 ratio in BV2 cells of different groups. Values are mean $\pm S D, n=3$ slices from 3 animals per group, $\star \star P<$

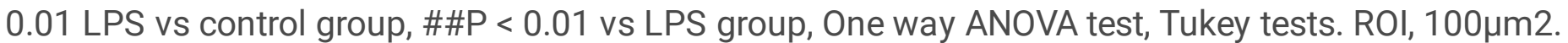
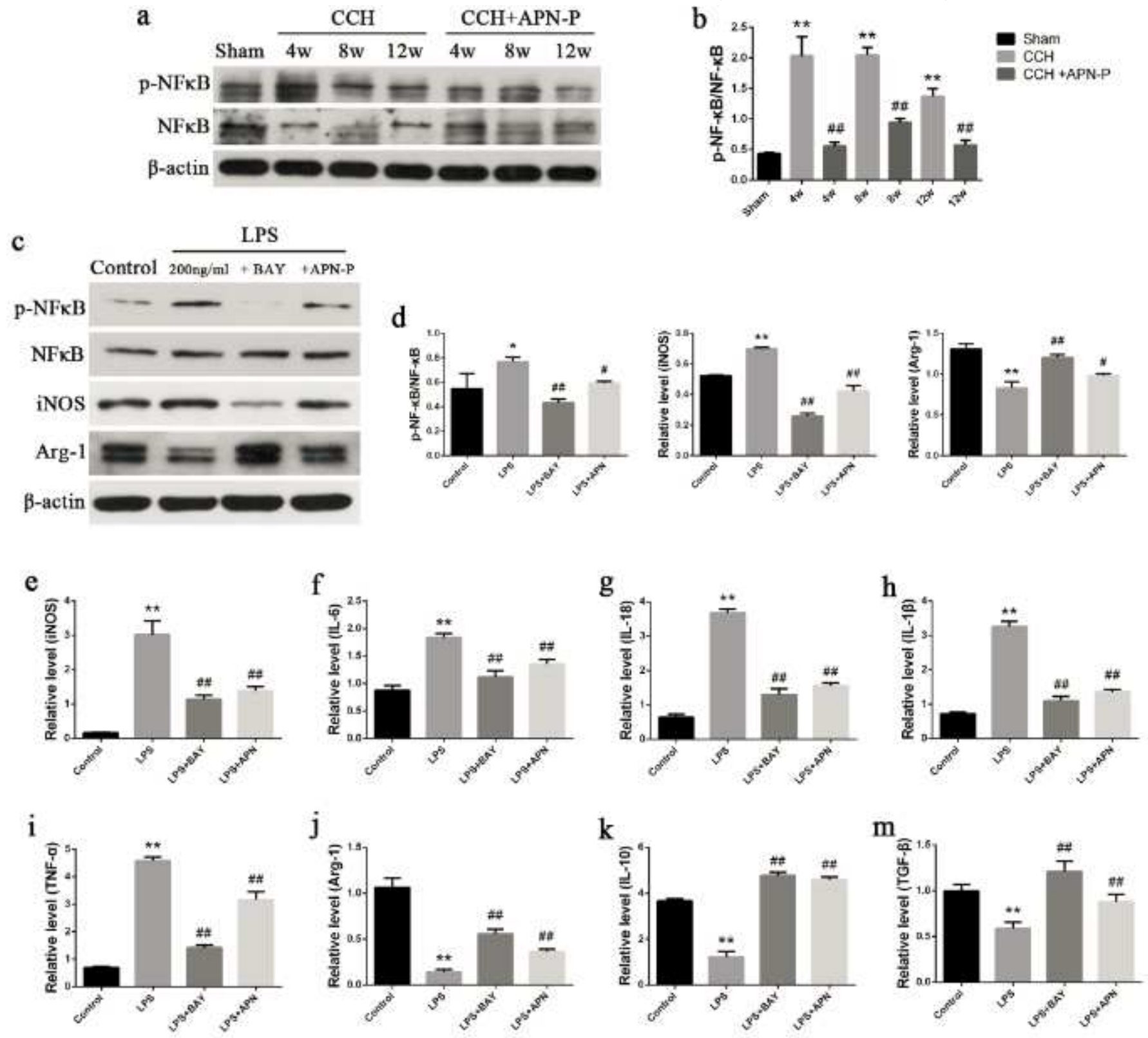

\section{Figure 5}

APN-P promotes the microglial M2 phenotype and anti-inflammatory responses via NF-kB pathway inhibition a. Western blotting analysis of in vivo NF-kB and p-NF-kB protein expression. b. Quantification of the in vivo $\mathrm{p}-\mathrm{NF}-\mathrm{kB} / \mathrm{NF}-\mathrm{kB}$ ratio. Values are mean $\pm \mathrm{SD}, \mathrm{n}=3$ samples per group, ${ }^{\star *} \mathrm{P} \otimes 0.01 \mathrm{CCH}$ vs sham group, \#\#P囚0.01 CCH+APN-P vs $\mathrm{CCH}$ group, One way ANOVA test, Tukey tests. c. Western blotting 
analysis of the protein expression of NF-KB, p-NF-kB, iNOS and Arg-1 in vivo. d. Quantification of the in vitro p-NF-KB/NF-KB ratio relative to iNOS and Arg-1 expression levels in control, LPS treatment, LPS + $B A Y$ and LPS $+A P N-P$ treated groups. Values are mean $\pm S D, n=3$ samples per group, ${ }^{\star} P<0.05, * * P \square$ 0.01 LPS vs control group, \#P < 0.05, \#\#Pख0.01 vs LPS group, One way ANOVA test, Tukey tests. The mRNA expression of (e) iNOS, (f) IL-6, (g) IL-18, (h) IL-1 $\beta$, (i) TNF-a, (j) Arg-1, (k) IL-10, and (m) TGF- $\beta$ in BV2 cells in different groups. Values are mean $\pm S D, n=6$ samples per group, ${ }^{\star * P} \otimes 0.01$ LPS vs control group, \#\#P囚0.01 vs LPS group, One way ANOVA test, Tukey tests.

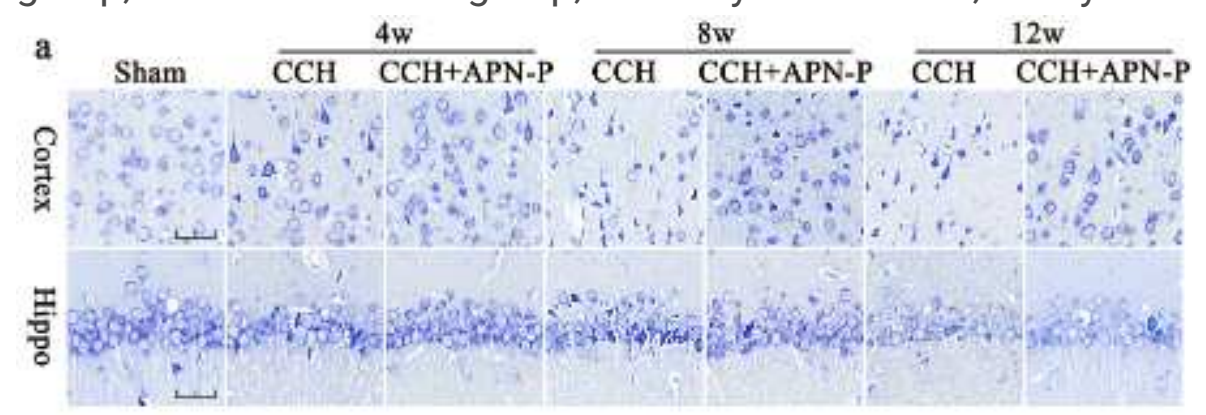

b

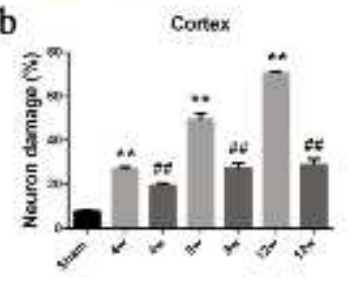

c

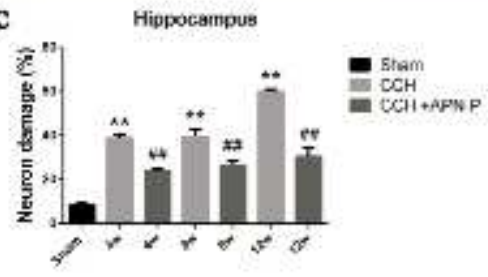

d

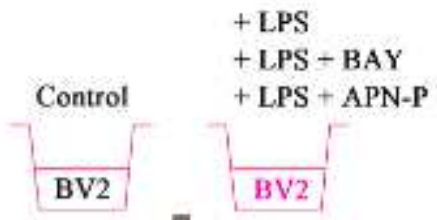

$48 \mathrm{~h}$

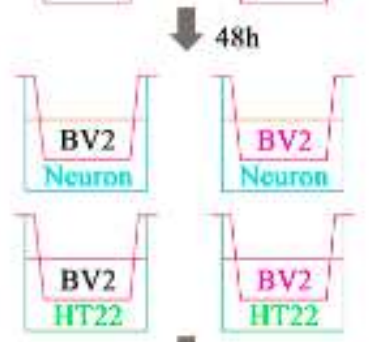

e cCK-8

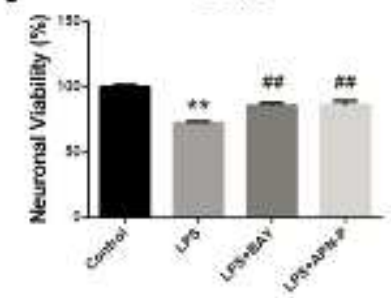

$48 \mathrm{~h}$

Cell Viability
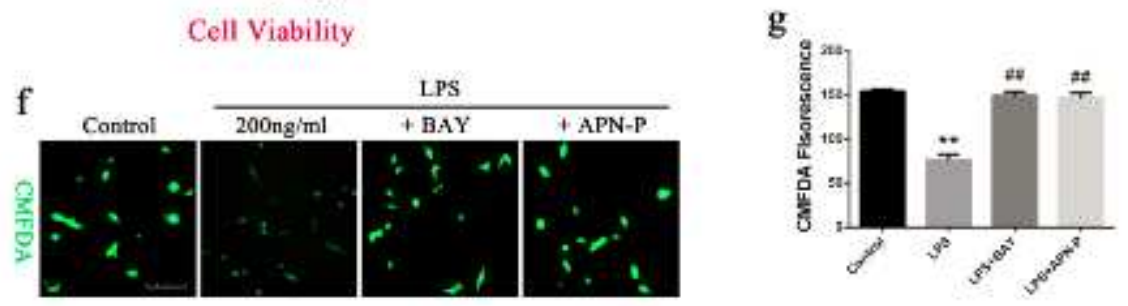

\section{Figure 6}

Effects of APN-P on neuron protection a. Sections of the cortex and the hippocampal CA1 region were obtained and treated with Nissl staining. Magnification $\times 40$, scale bar $=50 \mu \mathrm{m}$. b. Quantitative analysis of neuronal damage of the cortex region. c. Quantitative analysis of neuronal damage of the hippocampal CA1 region. Values are mean $\pm S D, n=3$ samples per group, ${ }^{\star *} \mathrm{P} \otimes 0.01 \mathrm{CCH}$ vs sham group, 


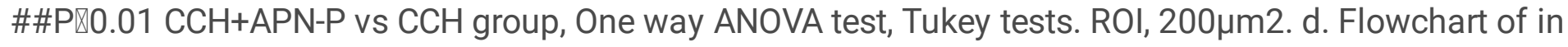
vitro experiments (a microglia-neuron co-culture system). e. Quantitative analysis of neuronal viability of BV2 cells from different groups after co-culturing using a CCK-8 test. Values are mean $\pm S D, n=5$ samples per group, **P $₫ 0.01$ LPS vs control group, \#\#P『0.01 vs LPS group, One way ANOVA test, Tukey tests. f. Representative images of CMFDA-labeled neurons (green) after co-culturing with different BV2 cells. Magnification $\times 40$, scale bar $=100 \mu \mathrm{m}$. g. The quantification of the CMFDA fluorescence intensity in

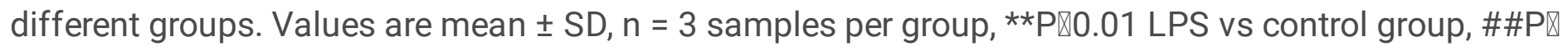
0.01 vs LPS group, One way ANOVA test, Tukey tests.

a

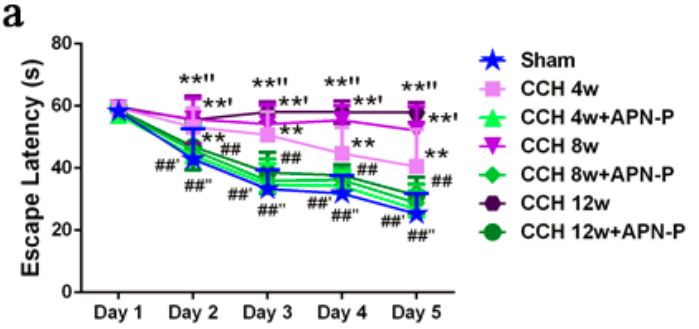

d

d

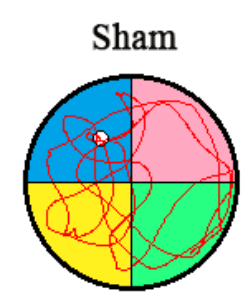

b

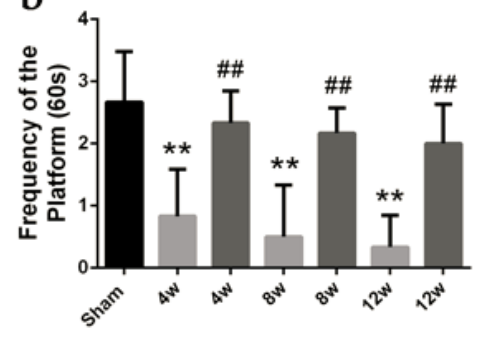

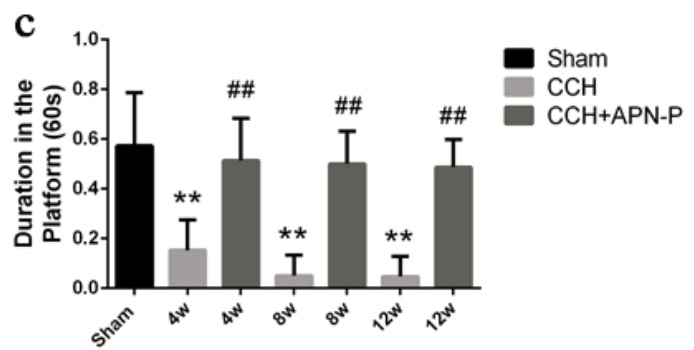

$8 \mathrm{w}$

$12 \mathrm{w}$

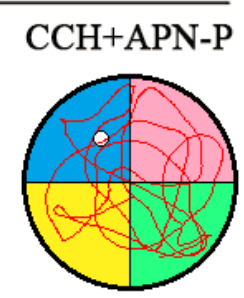

$4 \mathrm{w}$

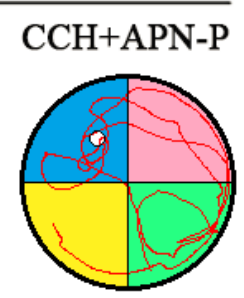

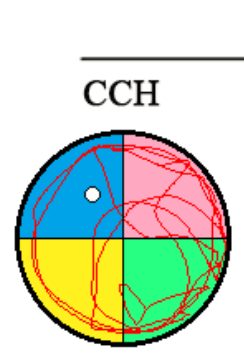

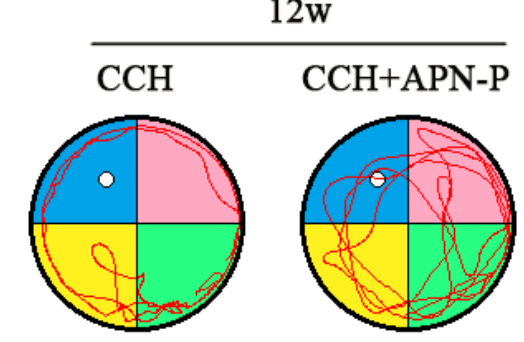

Figure 7

$\mathrm{CCH}$ exacerbates cognitive deficits, while APN-P improved cognitive function in rats a. EL of rats trained in a Morris water maze (day 1 to day 5 ). Values are mean $\pm S D, n=6$ samples per group, $* * P<0.01 \mathrm{CCH}$ $4 \mathrm{w}$ vs sham group, \#\#P<0.01CCH 4w + APN-P vs $\mathrm{CCH} 4 \mathrm{w}$ group; $* \star^{\prime} \mathrm{P}<0.01 \mathrm{CCH} 8 \mathrm{w}$ vs sham group, $\# \#{ }^{\prime} \mathrm{P}<0.01 \mathrm{CCH} 8 \mathrm{w}+\mathrm{APN}-\mathrm{P}$ vs $\mathrm{CCH} 8 \mathrm{w}$ group; ${ }^{\star \prime \prime} \mathrm{P}<0.01 \mathrm{CCH} 12 \mathrm{w}$ vs sham group, \#\#"P<0.01 CCH $12 w+$ APN- P vs CCH 12w group, Two-way ANOVA, Bonferroni post hoc test. b. Number of platform location crosses indicating that the $\mathrm{CCH}$ and $\mathrm{CCH}+\mathrm{APN}-\mathrm{P}$ treatment groups were significantly different from each other on day 6 . c. Stay time of each treatment group on the platform during a single 60-s probe trial (day 6). Values are mean $\pm \mathrm{SD}, \mathrm{n}=6$ samples per group, ${ }^{\star *} \mathrm{P}<0.01 \mathrm{CCH}$ vs sham group, \#\#P $<0.01$ $\mathrm{CCH}+\mathrm{APN}-\mathrm{P}$ vs $\mathrm{CCH}$ group, Two-way ANOVA, Bonferroni post hoc test. d. Representative images of the number of platform location crosses of each treatment group in the Morris water maze. 


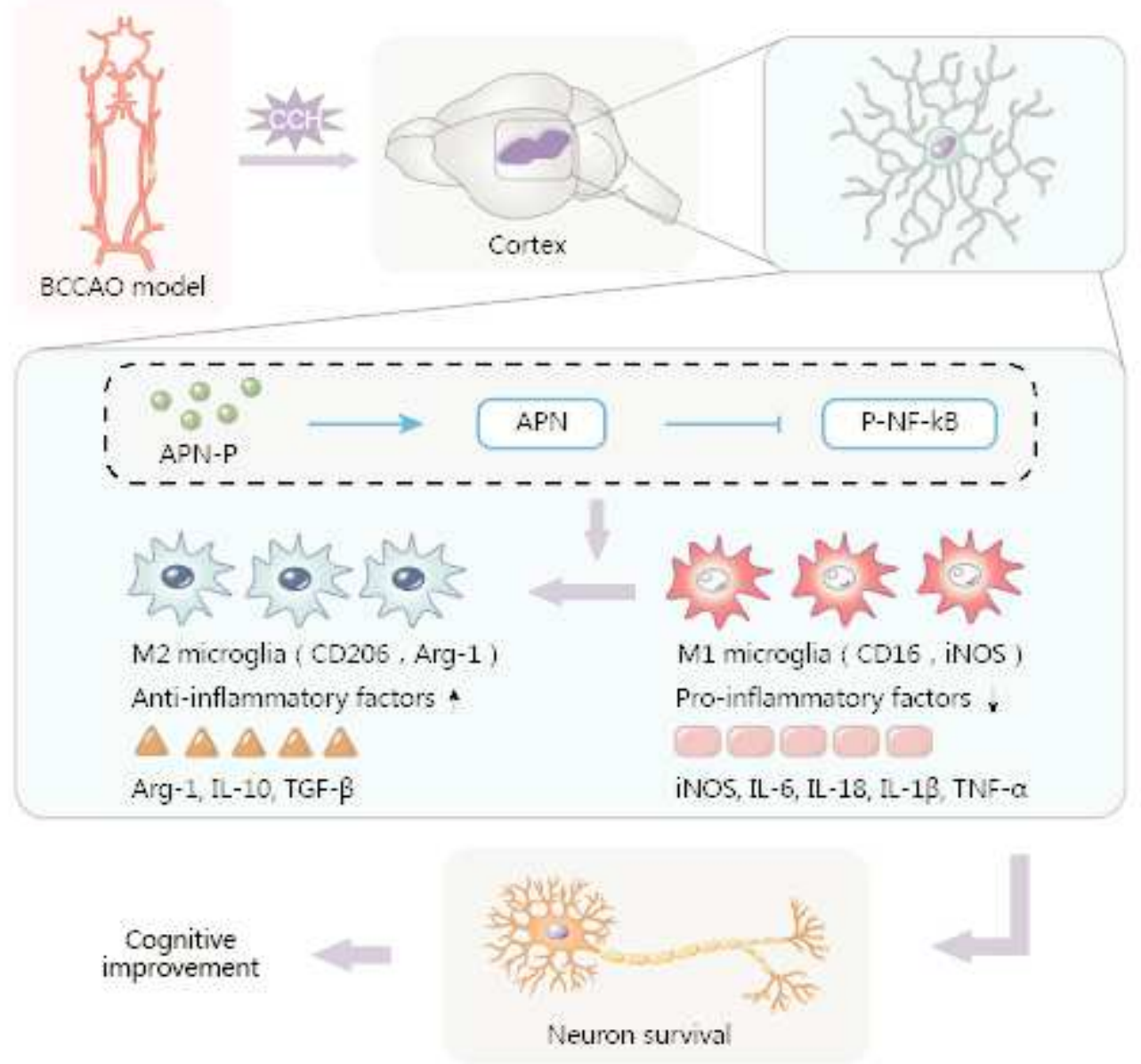

\section{Figure 8}

Graphical abstract APN-P inhibited the NF-KB pathway and regulated microglial polarization from an M1 toward an $\mathrm{M} 2$ phenotype, which alleviated the inflammatory response and cortical neural injury, rescuing $\mathrm{CCH}$-induced cognitive impairment.

\section{Supplementary Files}

This is a list of supplementary files associated with this preprint. Click to download.

- Additionalfile1TableS1.docx

- Additionalfile2FigureS1.tif 